\title{
El (DES) CONTROL DEL "Yo": FRONTERA Y SIMULTANEIDAD EN UNA ETNOGRAFÍA SOBRE LAS MIGRANTES PERUANAS EN ARICA (CHile)
}

\author{
Menara Guizardi ${ }^{1}$
}

\begin{abstract}
Resumen
Se analizan las formas de reorganización del "yo" de mujeres migrantes a partir de un estudio sobre la migración peruana en la ciudad chilena de Arica, en la frontera entre Chile y Perú. Luego de describir el contexto sociohistórico de la ciudad, detallaré la propuesta metodológica desarrollada para el estudio. De la mano de la perspectiva transnacional de los estudios de la migración, analizaré algunas consideraciones teóricas fundamentales sobre el concepto de simultaneidad, definiéndolo como una relación dialéctica en tres dimensiones, a partir de las cuales, se articulan formas contradictorias de subjetividad. Para ilustrar mis reflexiones, relataré ejemplos de situaciones y diálogos del trabajo de campo que evidencian las formas particulares de la construcción del "yo" por parte de mujeres migrantes, discutiendo su producción simultánea y transnacional.
\end{abstract}

Palabras clave: Migración transnacional, fronteras nacionales, género.

\begin{abstract}
The paper analyses the modes of reorganization of the "self" of migrant women in a study about the Peruvian migration in the Chilean city of Arica, in the border area between Chile and Peru. After describing the social and historical context of the city, I will detail the methodology developed for the study. Following the perspective of transnational migration studies, I will analyze some fundamental theoretical considerations on the concept of simultaneity, which will be defined as a dialectical relationship in three dimensions. To illustrate my reflections, I will narrate examples of situations and dialogues of the fieldwork which evidence the particular "self" constructions of Peruvian migrant woman. Through these examples, I will discuss the simultaneous and transnational production of migrant "selves".
\end{abstract}

Abstract

Keywords: Transnational migration, national borders, gender.

Recibido: Enero 2015. Aceptado: Septiembre 2015

\section{$*$ Introducción}

Ha pasado más de diez años desde que se publicó por primera vez en castellano el clásico texto de Kearney (2003) Fronteras y límites del Estado y el Yo al final del imperio. Las reflexiones que se despliegan en esta obra, no obstante, siguen martillando en la imaginación antropológica de muchos de los etnógrafos que trabajan en regiones fronterizas. El texto produce una inflexión potente al proponer una interseccionalidad entre los aspectos estructurales y las prácticas sociales, planteándolos como dimensiones dialécticamente imbricadas y que encuentran en los procesos de producción del "yo" su sedimento de materialización última y primigenia, simultáneamente. Kearney es perspicaz al alertar que esta producción del "yo" es, también ella, dialéctica. De ahí que el "yo" del antropólogo que trabaja en la frontera sea construido en un juego de contradicciones y continuidades - de rupturas y flujos, como dice Appadurai (2000:33)-, del que participan el "yo" del migrante y el "yo" de aquellos que, en uno u otro lado de la frontera, son considerados "autóctonos".

Con ello, Kearney pone de manifiesto algo central para la experiencia antropológica en la frontera: la reflexividad y la alteración del "yo" del etnógrafo, como contenido de las situaciones sociales y estructurales fronterizas. Su argumento nos indica que, allá donde los límites del Estado-nación se materializan -y acompañando todo el debate que en la antropología viene tensionando la naturalización conceptual del isomorfismo espacio-cultura

1 Instituto de Altos Estudios Sociales, Universidad Nacional de San Martín (Buenos Aires, Argentina) y Departamento de Antropología, Universidad Alberto Hurtado (Santiago, Chile) Universidad de Tarapacá (Arica, Chile). Dirección: Almirante Barroso, 10. Santiago (Chile). Email: menaraguizardi@yahoo.com.br 
(Clifford 1997a: 186, 1997b: 98-99, Gupta y Ferguson 1992: 6-7, 1997: 04) - también lo hace la urgencia de la construcción de formas críticas (y eminentemente autocríticas) de desarrollo del quehacer etnográfico.

Las fronteras nos plantean no solamente los límites e insuficiencias de la mirada que reifica las dicotomías analíticas. Ellas constituyen un territorio en el que los supuestos sobre espacio y lugar derivados de la observación participante malinowskiana caduca. Y lo hace por la insuficiencia explicativa de las bipolaridades que, como método, esta forma de etnografía supone $e^{2}$ la oposición entre el estar allá y estar acá (Burawoy 2000: 01; Passaro 1997: 148); la disyunción entre sujeto y estructura (Fabian 2002, 2007); la dicotomía entre lo local y lo extra-local (Appadurai 2000: 188), la bipartición entre lo particular y lo universal y, finalmente, la separación entre teoría y práctica (Evens y Handelman 2006: 1-5; Greenwood 2000: 30-35). Justamente a partir de las "angustias" (Marcus 1995) que la deconstrucción de las técnicas, habitus y arquetipos (Guizardi 2011: s/n) de la observación participante provoca, planteo en el presente artículo analizar las formas de reorganización del "yo" de los sujetos estudiados -y, no menos, del "yo-etnógrafa"en el marco de un estudio sobre la migración femenina peruana en la ciudad chilena de Arica, en la frontera entre Chile y Perú.

Luego de describir brevemente el contexto sociohistórico de Arica, detallaré la propuesta metodológica desarrollada para el estudio, la que articuló dos modelos etnográficos: el Extended case Method (ECM) (Burawoy 1998: 5; Evens 2006: 50; Gluckman 2006: 16-17) y la Etnografía Multisituada (EM) (Hannerz 2003: 202; Marcus 1995: 105). Acto seguido, y de la mano de la perspectiva transnacional de los estudios de la migración, detallaré algunas consideraciones teóricas fundamentales sobre el concepto de simultaneidad. En esta instancia, definiré el concepto como una relación dialéctica en tres dimensiones: 1) entre dos o más espacios locales separados por límites nacionales; 2) entre las formas de agencia y de estructura que inciden, entrecruzadamente, en los contextos de origen y destino; $y$, finalmente, 3 ) entre dos o más dimensiones de la experiencia del "yo" migrante. Para ilustrar este último aspecto, relataré ejemplos de situaciones y diálogos del trabajo de campo que evidencian las formas particulares de la construcción del "yo" por parte de mujeres migrantes. A partir de estos ejemplos, en las consideraciones finales discutiré la producción simultánea y transnacional del "yo" migrante.

\section{DEL CONTEXTO Y DE LA METODOLOGÍA}

La ciudad de Arica se ubica en el extremo norte de Chile, en el Desierto de Atacama. Es parte de un territorio conocido como "Norte Grande", que pertenecía a Perú y Bolivia y que terminó anexándose a Chile después de la Guerra del Pacífico (1879-1883)3. Tras el conflicto, las tierras al sur del antiguo departamento peruano de Tacna -al que pertenecían las ciudades "siamesas" Tacna y Arica (González 2008: 13)-, permanecieron en litigio y ocupadas por el ejército chileno. La situación se resolvió con el Tratado de Lima (1929): un acuerdo entre Estados que evitó la participación popular (González 2008: 14), definiendo que Tacna sería peruana y Arica chilena (Podestá 2011: 124). Entre ellas, se demarcó la "Línea de la Concordia", que determina hasta la actualidad la frontera entre ambos países (González 2008: 7).

Pese al periodo de litigio, el territorio anexado sufrió, durante toda la primera mitad del siglo XX, la persistencia de una política de chilenización (Díaz 2006: 300; González 1995: 43, 2004: 18). Ésta fue implementada por el Estado chileno desde fines del siglo XIX con la finalidad de asegurar en estos espacios la hegemonía de los ideales identitarios nacionales construidos centralmente por las élites santiaguinas (Guizardi y Garcés 2013: 67). Estos ideales planteaban una diferencia de civilidad entre chilenos, peruanos y bolivianos, enunciando ideológicamente a los segundos como indígenas y bárbaros (McEvoy 2011: 15). La chilenización se confundió tácitamente con la urbanización y con las des-indigenización de las poblaciones del Norte Grande, consolidando un proceso

2 Habría que hacer un paréntesis y matizar que la dicotomía analítica, en términos epistemológicos, es un componente de la ciencia que no se limita a la etnografía, ya que ha operado como una estructura formadora transversal del pensamiento social moderno (Comaroff 1985: 3; Grosfoguel 2008: 115).

3 El Norte Grande contempla tres regiones de la actual división político-administrativa chilena: Arica y Parinacota (cuya capital es Arica); Tarapacá (capital Iquique), y Antofagasta (capital Antofagasta). 
violento (González 2004: 19) que operó a través de la escuela pública (Cavieres 2006), de la Iglesia y de aparatos paramilitares y culturales (González 2004: 19).

En relación a esta política estatal chilena, habría que subrayar tres matices interpretativos de su trascendencia histórica. En primer lugar, apuntar que su incidencia en las diferentes regiones que componen el Norte Grande de Chile fue disímil. En la antigua región de Tarapacá, por ejemplo, la chilenización se dejó confundir muy agudamente con la represión al movimiento obrero, en parte, porque muchos de los trabajadores de las empresas salitreras eran de nacionalidad peruana y boliviana (González 2009: 76), y también porque la afinidad política y la orgánica sindical en la pampa del Tamarugal habían articulado redes de cooperación entre estos trabajadores y sus pares chilenos (González 1995: 45)4. Esto, lógicamente, no quita que la violencia se haya articulado de otras maneras en Tarapacá. A su vez, en los pueblos del altiplano situados en aquello que hoy es la Región de Arica y Parinacota, la violencia chilenizadora se hizo sentir muy fuertemente como una persecución a los indígenas aymara, que en gran medida permanecieron pro peruanos durante e inmediatamente después del conflicto (Díaz 2006: 299). Esta persecución se materializó, entre otras formas, a través de la escuela, con la castellanización forzosa (Díaz 2006:300), pero también con las violaciones a mujeres -fenómeno que por cierto se había convertido en una actividad constante de los militares chilenos desde la campaña militar de la Guerra del Pacífico (Sater 2007: 92)-5.

En segundo lugar, habría que subrayar que estas formas particulares y contextuales que la chilenización asumió en las diferentes localidades y regiones del Norte Grande de Chile se han transformado con el paso del tiempo, consecuencia no solamente por los cambios políticos del gobierno central chileno y su impacto en las relaciones con Perú y Bolivia (especialmente en lo que se refiere al tenso proceso de establecimiento de las fronteras entre los tres países), sino también por las oscilaciones del panorama económico internacional.

En tercer lugar, cuando la chilenización dejó de actuar abiertamente como una política estatal, las políticas de modernización y urbanización aplicadas diferencialmente en las ciudades nortinas, dieron continuidad al imperativo de transformar al norte y sus poblaciones, de acuerdo, a los ideales de progreso del centro de Chile (Valdebenito y Guizardi 2014: 280). Así, la finalización de la política chilenizadora no provocó una eliminación del ethos y del proyecto nacionalizador que en ella se proyectaba. Éstos se siguieron reproduciendo en las nuevas políticas de modernización que se desarrollaron en el norte de Chile hasta avanzada la segunda mitad del siglo XX.

Actualmente, Arica es un escenario urbano ${ }^{6}$ donde la construcción de la frontera nacional sigue en marcha y es evidente en la militarización de la ciudad y de su extrarradio ${ }^{7}$, y en la relevancia de imaginarios demarcadores de los "unos" y "otros". Todo esto implica un diálogo complejo con el pasado de circulación humana en estos territorios ${ }^{8}$, pero también con la intensificación coetánea de los flujos migratorios y comerciales entre Chile, Perú y Bolivia, en los cuales Arica participa activamente?.

4 Allá donde el sindicalismo sembraba sentimientos de una condición de clase compartida (que podría actuar en el sentido de eclipsar la diferencia de nacionalidad que el Estado chileno pretendía instaurar), la chilenización actuó incisivamente como un mecanismo de ruptura de los lazos y de la orgánica obrera. La violencia del Estado chileno en este proceso queda patente en las grandes matanzas obreras - como la de la Escuela Santa María en 1907 (González 2007: 19) - que se arrastran hasta las primeras décadas del siglo XX.

5 Se manifestó también ya en 1885 (tras dos años de finalizado el conflicto armado), a través de la nacionalización de las tierras agrícolas e instituir medidas de estatización y control sobre los territorios rurales antes comunales (véase en este sentido Gundermann 1998).

6 La ciudad contaba con 210.914 habitantes en 2012, la casi totalidad de la población de la Región de Arica y Parinacota que era de 213.595 personas (INE 2012: 58).

7 Es la ciudad con mayor contingente militar de Chile (Holahan 2005).

8 Investigaciones histórico-arqueológicas confirman la existencia de circuitos de movilidad humana de larga duración que atraviesan todo el Norte Grande, cruzando las actuales fronteras entre Perú, Chile y Bolivia (Núñez y Nielsen 2011).

9 Pese a contar con tan solamente el 1,29\% de la población total del país (INE 2012:15), Arica y Parinacota concentra el 3,6\% del total de migrantes en Chile, y es la cuarta región chilena en porcentaje de extranjeros (DEM 2012:3). 
Actuar como etnógrafa en un contexto como éste implica una reflexión previa sobre cómo hacer dialogar el método con la diacronía de las configuraciones locales. Esta dimensión diacrónica deja su marca en las movilidades y restricciones de flujo que se observan en tiempo presente en la frontera chileno-peruana. Pensando justamente en seguirle la pista histórica a los flujos a través de la frontera; y en detectar su incidencia en las rupturas y limitaciones a la movilidad migrante en Arica, diseñamos nuestras estratégicas metodológicas a partir del cruce de la etnografía multisituada y del Extended Case Method $(\mathrm{EMC})^{10}$.

Marcus (1995: 106-112) apunta siete tipos de estrategias etnográficas multisituadas que permitirían poner en suspenso (o relativizar) la noción de adscripción estática del grupo social al espacio. Combinamos cuatro de ellas en nuestra investigación. En un primero momento, seguimos a las personas, desplazándonos hacia los diferentes espacios donde los migrantes peruanos desarrollaban sus experiencias laborales, políticas, residenciales y de ocio en Arica. En segundo lugar, seguimos a los conflictos, acompañando procesos de contienda y desacuerdo que involucraban a migrantes, instituciones del Estado y población chilena. En tercer lugar, seguimos a la biografía, desarrollando entrevistas de historia de vida con las mujeres peruanas. A partir de estos relatos, recopilamos las historias migratorias en las familias nucleares y extensas, y los desplazamientos transfronterizos por ellas vividos. Finalmente, desarrollamos etnografía estratégicamente situada en puntos clave para la experiencia migrante de la ciudad. Identificamos especialmente tres puntos que organizaban el tránsito, flujo y fijación de los peruanos a través de la ciudad: el Terminal Internacional Rodoviario (y los sectores aledaños), el Agromercado, y los campamentos Coraceros y Areneros (barrios de toma y ocupación) de Arica.

En estos espacios, y en nuestro movimiento a través de ellos, adoptamos una forma específica de focalizar las escenas y prácticas sociales de las que participábamos. Inspirándonos en el Extended Case Method, concentramos la mirada etnográfica en aquello que Gluckman (2006) denominó situaciones sociales o "trouble situations" (Evens 2006: 53). Éstas configuran incidentes serios y dramáticos; relaciones sociales tensas, inestables, traspasadas por una conflictividad latente y/o manifiesta en la que condiciones estructurales son apropiadas por la agencia subjetiva, sin perder su dimensión restrictiva (Guizardi 2012: $\mathrm{s} / \mathrm{n}$ ). Estas situaciones son un punto clave si se pretende superar la dicotomía analítica entre agencia y estructura, puesto que permiten al etnógrafo observar los procesos de adecuación (asimétricos, desiguales y contradictorios) entre coerción social y acción individual (Gluckman 2006: 16). Esto deviene del hecho de que estas experiencias del conflicto obligan a los sujetos a "situarse": a paradójicamente tomar partido restringiendo su acción a una interpretación específica de los valores; operando un diálogo cotidiano entre sus sentidos e intenciones particulares, el de los sujetos con que se interacciona y los condicionantes históricos que configuran los espacios en los que estas situaciones tienen lugar ${ }^{11}$.

Las incursiones a terreno dieron origen a un material descriptivo-analítico compuesto de un total de 47 relatos semanales (recopilando las experiencias diarias en terreno), y un registro fotográfico de los espacios estudiados (140 fotografías catalogadas/clasificadas). Complementando este material realizamos un total de 91 entrevistas cualitativas, las cuales fueron registradas digitalmente, transcriptas y trabajadas a partir del análisis de discurso (con apoyo del Software MaxQDA). Entre ellas, se contabilizan: 32 historias de vida con mujeres peruanas, 10

10 La etnografía que da origen al presente artículo fue realizada entre noviembre de 2012 y julio de 2013, enmarcándose en un proyecto de tres años -iniciado en octubre de 2012 y con término previsto para octubre de $2015-$. El proyecto analiza comparativamente la experiencia migratoria de mujeres peruanas en tres ciudades chilenas: Arica e Iquique (en el norte del país), y Valparaíso (en el centro de Chile). El equipo que desarrolló el estudio de caso en Arica contó también con Felipe Valdebenito, Grecia Dávila y Orlando Heredia (estudiantes de antropología de la Universidad de Tarapacá. Arica, Chile), y Arlene Muñoz Droguett (socióloga del Centro de Investigaciones del Hombre en el Desierto. Arica, Chile). El proceso de análisis de las informaciones contó con las labores de Esteban Nazal (antropólogo de la Universidad de Chile) y Eleonora López (socióloga de la Universidad Nacional Autónoma de México).

11 En síntesis, asumimos las situaciones sociales como "the operation of constraining social force (...). It was the force of the norms in the conflict that constrained, whereas the interactional event was determined by the forces of the social structure at large, the 'large scale'. It was indeed such social constraint that described what it means to be 'situated"' (Evens 2006: 53). 
entrevistas semiestructuradas a hombres peruanos, 21 entrevistas semiestructuradas a funcionarios y voluntarios de ONG de atención a migrantes, 15 entrevistas semiestructuradas a mujeres peruanas en la Cárcel de Acha (Arica), 3 entrevistas a líderes comunitarios en barrios de concentración migrante, además de 6 entrevistas con mujeres bolivianas en estos barrios.

\section{DEBATES TEÓRICOS DE PARTIDA: (RE) CONCEP- TUALIZAR LA SIMULTANEIDAD}

El título de este apartado encierra una relación metonímica con el (también clásico) texto de Levitt y GlickSchiller (2004), "Conceptualizando la simultaneidad". La añadidura del prefijo "re" al "conceptualizar" explica, en gran medida, el objetivo del apartado: definir la necesidad de redimensionar esta simultaneidad tratándola enfáticamente como un proceso dialéctico. No obstante, antes de entrar en este debate, conviene reseñar (aunque brevemente) el papel que el concepto de simultaneidad ha desempeñado en la estructuración de la perspectiva transnacional de las migraciones y en la comprensión de territorios fronterizos.

En este sentido, y de cara a vincular estos debates teóricos con el estudio de caso específico que abordo aquí, partiré por enunciar que la condición fronteriza de Arica altera la manera como agencia y estructura se retroalimentan en la construcción de "lo local". Según Kearney (2003: 47-48), las fronteras nacionales constituyen espacios sui generis que desafían la fijación de las bipolaridades modernas y los principios definitorios de "lo nacional": la separación (étnica, fenotípica, cultural) entre los "unos" y los "otros" y la limitación espacialmente demarcada de aquello que pertenece a la nación. Esto, no obstante, no elimina las tensiones estructurales que inciden sobre estos espacios. En ellos, el Estado sigue imponiendo (o intentando imponer) sus configuraciones jurídicas, militares y políticas ${ }^{13}$. A la vez que los procesos económicos macro-estructurales siguen imponiendo su peso definitorio sobre las prácticas micro-sociales y locales (Kearney 2003: 52).

En los debates sobre migración ha predominado la concepción de que la condición transfronteriza de los migrantes internacionales les convierte en "transmigrantes", materializándose como un conjunto de prácticas transnacionales, que consisten en la generación de campos sociales que vinculan de maneras diversas el país de origen con el de destino. Esta noción recupera las categorías de Bourdieu, quien comprendía el campo "como una esfera de la vida social que se ha ido autonomizando de manera gradual a través de la historia en torno a cierto tipo de relaciones, intereses y recursos propios" (Manzo 2010: $398)^{14}$.

Se ha ido forjando una cierta condensación teórica alrededor de esta dimensión transnacional de la experiencia migrante, articulándose en esta perspectiva una serie de debates que vienen centralizando gran parte de las investigaciones sobre la migración internacional en las ciencias sociales. Así, transnacionalismo es un término que se viene usando -muy polisémicamente, por cierto (Besserer 2004: 1; Monteczuma 2008: 42)- para designar al complejo conjunto de prácticas migrantes que provocan una vinculación que relativiza el ser, estar y pertenecer al Estado-nacional. Según Glick-Schiller et al. (2005: 68), los transmigrantes, "desarrollan y mantienen múltiples relaciones -familiares, económicas, sociales, organizacionales, religiosas y políticas que atraviesan las fronteras-". Además, "toman medidas, decisiones, tienen

12 Desde este punto de vista, las fronteras nacionales constituirían espacios cruzados por prácticas que no se reducen a la lectura euclidiana de las identidades nacionales (Brenna 2011). Estos territorios, más que dibujados como líneas literales de separación entre una nación y sus otros externos - como los mitos fundadores de los Estados-nacionales los enuncian (Segato 2007)-, constituirían espacialidades con algún grado de porosidad (Grimson 2005).

13 Los territorios fronterizos están, consecuentemente, cruzados por tres dimensiones políticas constitutivas de su espacialidad (Kearney 2008). Las fronteras literales, materializadas como demarcaciones político-territoriales; las identidades cruzadas por las variables de etnia, clase y nacionalidad y los regímenes políticos (entidades oficiales y no oficiales encargadas de trazar y hacer respetar los límites políticos-identitarios).

14 Consecuentemente, los campos sociales serían cruzados por luchas y fuerzas tendientes a la transformación y, simultáneamente, a la conservación. Funcionan debido a que los agentes "invierten en él, en los diferentes significados del término, que se juegan en él sus recursos [capitales], en pugna por ganar" (Bourdieu en Manzo 2010:398). 
intereses y desarrollan identidades dentro de las redes sociales que los conectan con dos o más sociedades ${ }^{\prime \prime 15}$. Esta condición genera una experiencia social de simultaneidad: un estar en origen y destino al mismo tiempo en que se reconfiguran los espacios locales de los países que reciben a los migrantes, desbordando (Garcés 2007: 18) ${ }^{16}$ en ellos formas, experiencias, olores, sabores y maneras de ser que fueron (espacialmente) producidos en sus localidades de origen y en otras localidades donde hayan vivido. $\mathrm{O}$, bien también, en aquellas localidades con las que los migrantes están conectados a través de sus redes sociales (Levitt y Glick-Schiller 2004).

Este uso del concepto de simultaneidad constituye una herramienta potente en el sentido de redimensionar las formas como, tradicionalmente en las ciencias sociales, hemos pensado la relación entre espacio, práctica social y cultura. No obstante, quisiera sugerir la necesidad de definir este concepto a partir de una lectura que subraya tácitamente las contradicciones inherentes a aquellas prácticas transnacionales a las que definimos como simultáneas.

Desde mi punto de vista, la materialización de una experiencia migratoria transnacional se vincula ontológicamente a la vivencia, por parte de los sujetos y colectivos, de tres dimensiones de simultaneidad. Son estas tres dimensiones articuladas -en un proceso que es siempre contextual y dinámico, operando muy a menudo de forma conflictiva, asimétrica y desigual- las que permiten la construcción de la compresión espacio-temporal (Harvey 1989) que subyace a toda y cualquier forma de simultaneidad social.

En otras palabras, para que los sujetos o colectivos migrantes sean capaces de construir en las localidades de destino una experiencia cotidiana que impacta, altera $y / 0$ que influya dinámica y simultáneamente a otros espacios locales, es necesario que logren articular de forma coherente, a modo de praxis social situada y cotidiana, tres dimensiones dialécticas de la experiencia de compresión espacio-tiempo ${ }^{17}$.

\section{Simultaneidad como relación dialéctica entre un allá y un acá}

La primera de estas dimensiones dice relación con la articulación espacial: con la construcción social del espacio en el que se vive, trabaja y transita en la sociedad de destino, actualizando en él prácticas, relaciones, identidades, afectos, deseos y jerarquías sociales (y, no menos, jerarquías de distinción) que devienen de las experiencias vividas en las localidades de origen o en otras localidades en las que se haya estado previamente. Cuando prácticas nacidas en contextos específicos logran viajar (producto del desplazamiento migratorio), provocan que espacios entre los que puede no haber una continuidad geográfica (en términos euclidianos) vayan superponiéndose a través de la experiencia migrante. De ahí que se preconice dar centralidad a la espacialidad transnacional de las comunidades y sujetos basándose "no en la distancia que las separa, sino en la densidad y frecuencia de las prácticas comunitarias que les acerca" (Besserer 2004: 8). Así, el transnacionalismo migrante incide en la construcción de formas diferentes de capital social y cultural $^{18}$-que viajan

15 Complementando este enfoque, Kearney (1995: 548) subraya el contenido político de la experiencia de transnacionalismo migrante, enfatizando que ésta tensiona proyectos político-culturales de los Estados-nación, los cuales buscan hegemonizar procesos con otros Estados, con sus propios ciudadanos y con sus "aliens".

16 Este concepto de desborde espacial se inspira en el debate de Appadurai (2000) sobre los procesos globales de flujo y su capacidad de romper la relación isomórfica entre "lo local" y "las prácticas sociales".

17 Cuando me refiero a que estas dimensiones se estructuran a modo de relaciones dialécticas, estoy suscribiendo a la definición de Jean Comaroff (1985), para quien los procesos dialécticos se constituyen a partir de dos relaciones: entre acción humana y constricción estructural y entre dominados y dominadores en el orden social. Aun así, la relación dialéctica implica considerar que los seres humanos actúan en la determinación de su propia historia, pero a través de mecanismos eminentemente contradictorios: "en la producción cotidiana de bienes y significados, ceden y protestan, reproducen y buscan transformar su situación" (Comaroff 1985: 1).

18 Por capital social migrante entendemos: "the aggregate of the actual or potential resources which are linked to possession of a durable network of more or less institutionalized relationship of mutual acquaintance or recognition" (Bourdieu en Portes 2000: 45). Esta red duradera no es naturalmente dada, tejiéndose a partir de estrategias orientadas a la institucionalización de las relaciones de grupo (Portes 2000) y puede definirse como 1) las relaciones sociales de estos migrantes en sí mismas, cuando dan acceso al conocimiento y a los recursos de que disponen los miembros de la red; y 2) la cantidad y calidad de recursos (Portes 2000: 45). El capital cultural correspondería justamente a los conocimientos y recursos incorporados por los migrantes. 
desde otros lugares, transportados por los migrantes de forma incorporada.

Esta definición reitera la que he presentado al inicio del apartado. Ella ha sido la forma como se ha definido más usualmente la simultaneidad transnacional, asociándola a la construcción de un campo social y a los debates sobre la espacialización de la realidad social que devienen de las reflexiones de Pierre Bourdieu. Pero quisiera subrayar algo que no siempre se ha asumido muy claramente en esta definición del campo trasnacional: su faceta ontológicamente dialéctica, derivada del hecho de que construye un espacio local a partir de la inscripción en él de prácticas extra-locales ${ }^{19}$. Esta relación dialéctica se inscribe en la contradicción compositiva de lo local-global que analiza Appadurai (2000). Cuando los migrantes viven y actúan en las localidades de recepción, articulando sus capitales y construyendo un campo social que conecta con su origen, erosionan a la vez que construyen el carácter espacialmente situado de la localidad.

Erosionan porque hacen de lo local algo que está dinámicamente (y desbordadamente) vinculado al extra-local; y construyen localidad, en la medida en que esta forma de conexión de lo local ha devenido estructuralmente general a partir de la globalización (Appadurai 2000) ${ }^{20}$. Lo que, no obstante, no se refiere solamente a la acción de los migrantes, guardando una vinculación también ontológica con la conformación del modo capitalista de producción desde fines del siglo XX: con la generalización de la especialización flexible del posfordismo (Harvey 1989), con una nueva situación poscolonial (Gupta 1992) y con la aceleración de los flujos - de gentes, mercancías y conocimientos - tras la globalización (Bauman 2006).

\section{Simultaneidad como dialéctica entre agencia y estructura}

Lo que he planteado anteriormente nos deriva a la segunda dimensión dialéctica de la experiencia de simultaneidad transnacional. La primera dimensión que describí, en la medida en que deviene en la articulación de capitales diversos entre localidades separadas por fronteras nacionales, depende de que los migrantes sean capaces de hacer dialogar de forma circunstancial y local la adaptación situacional de estos capitales. Esto, a su vez, requiere la capacidad de moldear, superar, reinventar y articular los conocimientos propios de acuerdo a las restricciones, constricciones y límites estructurales que se materializan en el espacio local que recibe a los migrantes. En otras palabras, la simultaneidad se materializa también como una forma de diálogo activo - cotidiano y práctico- entre los sujetos y colectivos y las restricciones estructurales del contexto de recepción.

Esta dimensión estructural se refiere, por ejemplo, a la construcción de dinámicas macro-económicas de explotación de la mano de obra migrante que tienen carácter nacional y global ${ }^{21}$. O bien también, a la conformación de exclusiones jurídico-políticas que permiten la reproducción de la exclusión económica. Estas dos características están entrecruzadas por la construcción asimétrica de las jerarquías de género y del mercado laboral a escalas globales, aspecto del todo importante para comprender la experiencia social de las mujeres peruanas en Arica. La inserción socioeconómica de estas mujeres reordena (y reactualiza) a escalas locales sistemas globales de explotación y las jerarquías de género ${ }^{22}$. Este proceso es interseccionalmente impactado por las desigualdades étnicas, de clase, de edad y de pertenencia nacional que definen los espacios, derechos y posibilidades de incorporación social de las mujeres (Crenshaw 1991: 1244).

19 Esta misma inscripción provoca - contradictoria y dinámicamente - la extra-localización de lo propio, en la medida en que los migrantes transmiten a sus redes sociales extra-locales sus aprendizajes sobre las prácticas autóctonas, que serán reactualizadas a partir de estas redes en un "más allá" de la localidad en que surgieron.

20 O, en las palabras de Comaroff (1985: 3): “ambos sistemas, el local y el global son al mismo tiempo sistemáticos y contradictorios; y ellos se convierten involucrados el uno con el otro en relaciones caracterizadas tanto por la simbiosis, como por la lucha".

21 Especialmente si observamos, como Wallerstein (2006), que la articulación de lo nacional deviene de un modo de producción y reproducción del capital que moldea la articulación entre los espacios nacionales y el lugar de cada nación en la geopolítica del sistema-mundo.

22 Alrededor del mundo, las jerarquías de género son producidas y mantenidas en relación con los circuitos transnacionales "of labor mobilization and capital accumulation. In varied and often locally specific ways international capital relies on gendered ideologies and social relations to recruit and discipline workers, to reproduce and cheapen segmented labor forces within and across national borders" (Mills 2003: 42). 
La condición femenina es un factor de diferenciación social en el sistema global de explotación de la mano de obra, que se materializa siempre de forma contextual, acorde a las particularidades de cada localidad. De ahí que, al pensar la simultaneidad como una relación dialéctica entre agencia y estructura, debemos reconocer aspectos estructurales incidiendo desigualmente sobre hombres y mujeres y que en esta desigualdad de género opera a la vez una dialéctica entre lo global y lo local. Consecuentemente, una mirada que busca entender la articulación de las identidades de clase social, etnicidad y de condición transfronteriza, por parte de las mujeres migrantes, sólo puede ser atingente si logra engendrarse a partir de un enfoque de género transversal.

Por "enfoque de género transversal" comprendo la perspectiva empírico-epistemológica de que las desigualdades de género operan, simultáneamente, como sistemas de significados y simbolismos dominantes; como relaciones sociales estructuradas, roles, y prácticas; y como prácticas cotidianas de identidad social: "gender meanings, relations, and identities do more than merely sustain existing structures of power in global labor relations; these complex dimensions of gender also constitute a dynamic cultural terrain wherein forms of domination may be contested, reworked, and even potentially transformed" (Mills 2003: 42).

Pero, y fundamentalmente para el caso que nos toca, la materialización de estas restricciones estructurales y de las asimetrías de género en el espacio local es siempre de carácter histórico. Ella recupera procesos de larga y mediana duración que han configurado la construcción de las identidades locales $y$, no en menor grado, la forma como la localidad ha absorbido e integrado el proceso de construcción de lo nacional. Esta relación histórica, particular e irreproducible de composición de las identidades locales, adquiere, así, los contornos de una contextualidad radical que opera a medio camino-produciendo, a la vez que rompiendo- los mitos autonormativos del proyecto cultural e identitario nacional.

Esto porque la composición de los paradigmas étnicos nacionales (Segato 2007) se elabora desde la enunciación modernamente universalista que pretende la homogeneidad constitutiva -cultural, fenotípica, e incluso racial- de la nación (Hobsbawn 1998). Una universalidad que será dialécticamente destruida en la medida en que el Estadonación obligue la materialización de estos ideales en los espacios locales. En síntesis, la contextualización de lo nacional en las localidades, en especial en las de frontera (donde el Estado recuerda y es recordado de sus límites), destruye el universalismo de la nación en la misma medida en que le dota de materialidad contextual y particular. Y lo curioso es que esta materialización en las localidades es condición sine qua non de existencia del proyecto universalista del Estado nacional. En este sentido, y siguiendo a Grimson (2011: 172), podríamos afirmar que los espacios locales, y en especial espacios fronterizos como Arica, constituyen una configuración cultural ${ }^{23}$.

Pensar en configuraciones culturales nos dirige hacia una mirada que centraliza el contexto de construcción de las identidades como parte de un campo de disputas que es eminentemente político. Al mismo tiempo, nos lleva a indagar en la cristalización de lo cultural como un elemento que, en la zona de frontera, particulariza los contenidos de las adscripciones nacionales chilenas y peruanas, así como los entendimientos acerca de la relación entre las identidades étnicas y las nacionales ${ }^{24}$.

23 Cuatro serían las dimensiones constitutivas de las configuraciones culturales. Por un lado, ellas son campos de posibilidad (Grimson 2011: 172): se refieren a las instituciones, representaciones y prácticas que en determinado contexto son posibles, las que en este mismo contexto serían imposibles, y aquellas que devienen hegemónicas. En segundo lugar, las configuraciones culturales suponen que, en determinado contexto, las acciones, formas de ser y enunciar, relaciones, experiencias y conocimientos guardan algún nivel de interrelación entre sí, pero esto no deriva en una homogeneidad constitutiva. La configuración cultural sería así, doblemente, heterogénea y heterotópica (Grimson 2011: 176). A su vez, y en tercer lugar, para ser articulada, ella requiere de una trama simbólica común, que permita vincular, aunque heterogéneamente, una cuarta dimensión: la configuración resguarda, aun cuando asimétricamente, algo que es común y compartido (Grimson 2011: 177).

24 Esta dimensión política del fenómeno, a su vez, nos dirige al debate de Barth (1976: 30-31) sobre la relación entre las interacciones interpersonales y los procesos de cambio identitario en contextos en que un determinado grupo se ve presionado a adherir a los patrones (morales, axiológicos, culturales, económicos y políticos) de un grupo dominante. Barth propone este debate en relación a las identidades étnicas, pero sus reflexiones pueden aplicarse también a las comunidades migrantes y a las 
Comprender el espacio de recepción de los migrantes como una configuración cultural implica una analítica recíproca difícil de evitar: la consideración de que los espacios de origen de los migrantes también constituyen configuraciones culturales particulares en el marco de proyectos nacionales igualmente particulares. En esta medida, al considerar que la experiencia de simultaneidad transnacional, en su segunda dimensión, remonta a una relación dialéctica entre la agencia de los migrantes -la adaptación situacional de sus capitales sociales, económicos, simbólicos, políticos y culturales- y fenómenos estructurales macro-sociales; tenemos que considerar también que esta relación agencia-estructura opera a través del diálogo entre por lo menos dos configuraciones culturales. Aquella de la que proviene el migrante, y aquella a la que llega. Esto implica que los migrantes transiten entre dos estructuraciones particulares de lo nacional en lo que concierne a la asignación de identidades y pertenencias. Estos aspectos son indisociables de los factores estructurales económicos en la misma medida en que también lo son de las restricciones y posibilidades políticas vividas por los migrantes.

Pero la operación de adaptaciones situacionales de los capitales por parte de los migrantes no provoca la erosión completa de su subordinación, haciéndoles entrar a un mundo social donde los límites estructurales dejan de existir o cesan su efecto. Al mismo tiempo, la permanencia, reproducción e insistencia de las limitaciones estructurales no implican un total sometimiento del sujeto migrante en pos de una reproducción tácita de lo estructural. Ni bien al cielo, ni bien a la tierra: la simultaneidad implica que dialéctica, contradictoria y dinámicamente, reproducción y rupturas de lo estructural, se articularán a través de la agencia.

Un ejemplo ayudará a disolver posibles ambigüedades. En Arica, el hecho de que el Estado chileno haya militarizado la ciudad hasta convertirla en la principal concentración de fuerzas y armas del Ejército nacional; el hecho de que operen mecanismos fiscalizadores aduaneros que seleccionan discrecionalmente, limitando y dificultando los procesos de desplazamiento de ciertos sectores sociales peruanos hacia Chile; o el hecho de que el mercado laboral ariqueño haya institucionalizado la reproducción de la indocumentación migratoria como forma de plusvalía, constituyen todos aspectos estructurales que im- pactan decisivamente la experiencia local migrante. No obstante, simultáneamente a todas estas imposiciones, también actúan los migrantes: cruzando las fronteras por pasos no controlados, tramando estrategias colectivas de negociación del valor de la mano de obra indocumentada (Guizardi et al. 2014), estableciendo negocios adornados con los colores de sus banderas nacionales justo al lado de los regimientos militares (y serán los mismos militares quienes consumirán los servicios y productos de estos comercios). En fin, las restricciones estructurales no impiden la existencia de agencia; y la agencia no implica la erosión de las restricciones estructurales ${ }^{25}$.

Esto, a su vez, nos dirige a una crítica de la forma como el concepto de control social ha operado en el argumento de autores como Foucault (2004), especialmente en obras como Vigilar y Castigar. Las experiencias de simultaneidad transnacional son un claro ejemplo de procesos que desafían la noción estructuralista de reproducción del control

negociaciones adaptativas que éstas protagonizan. Barth asume que en ciertos contextos de "asimilación" de un grupo por otro, es posible que los sujetos asuman conductas, formas de hacer e interpretar las cosas del grupo dominante. Pero al hacerlo, los sujetos continúan enunciando su identidad y pertenencia al colectivo de origen, sin entender estas adaptaciones como una contradicción identitaria (Barth 1976:31). El autor contempla así un tipo de experiencia identitaria en situaciones de encuentro entre grupos diferenciados que se asemeja a lo que entendemos como las dinámicas sociales de las configuraciones culturales (en las que una interacción dialógica y dialéctica construye semejanzas sin implicar la desaparición de la diversidad, jerarquías y diferencias). Esta perspectiva implica asumir que el foco de la investigación es la forma como el grupo social y los sujetos construyen los límites de su colectivo identitario, y no los supuestos contenidos culturales que esta limitación encierra (Barth 1976: 17). Esta perspectiva de-sustantiva la cultura y centra el foco analítico en los procesos, más que en sus cristalizaciones (materiales o inmateriales).

25 Y por ello, como dijo Bourdieu (2011: 31), hay que “(...) rechazar tanto la visión 'estructuralista', según la cual las estructuras, portadoras del principio de su propia perpetuación, se reproducen con la colaboración obligada de agentes sometidos a sus constricciones, cuanto la visión interaccionista o etnometodológica (o, en términos más amplios, marginalista), según la cual el mundo social es producto de los actos de construcción que en cada momento realizan los agentes, en una suerte de 'creación continua"." 
por sobre la capacidad de agencia subjetiva o colectiva. Las estrategias conscientes o inconscientes de control social no siempre acompañan el desarrollo de estas "insubordinaciones" de la agencia ${ }^{26}$.

Todo esto me ha hecho pensar, a lo largo de mi trabajo de terreno con hombres y mujeres peruanos en Arica, que la condición de simultaneidad transnacional requería algo más de parte de los sujetos. Requería de los sujetos migrantes actuar situándose adentro y afuera de los capitales -sociales, culturales, simbólicos- que le constituían en cuanto partes de una sociedad, como integrantes de contextos sociales situados.

Con esto llegamos a la tercera de las relaciones dialécticas que componen la experiencia de simultaneidad transnacional: la que se refiere a la construcción del "yo" migrante como la producción de una sincronicidad entre ser el "uno" y ser el "otro". De cara a construir esta tercera dimensión de forma más incorporada, conviene antecederla de algunos relatos y situaciones vividos junto de las mujeres peruanas en Arica.

\section{Negociaciones del "yo"}

Ricouer (2006: xii-xiv) solía considerar los procesos de identidad como una compleja relación de comparación entre el "uno" y su "otro". Esta comparación, no obstante, se engendraría a partir de la constitución histórica de formas de narrativa sobre la pertenencia y diferencia, operando tanto en el marco de la formación de la identidad individual, como en la identidad colectiva de un grupo, comunidad o nación ${ }^{27}$. Afirmaba, además, que esta comparación guardaba una doble dimensionalidad. La formación de la percepción del "yo" -ya sea colectivo o individual- sobre sí mismo implicaría un principio autorreconocido de unicidad: el "yo" considerando y reconociendo aquello que en él es único; aquello que difiere, que no está en el "otro" externo. Esto equivale a decir que uno de los soportes de la condición de identidad se refiere a la construcción de una noción de singularidad que se incrustará en las mentalidades, narraciones, en las disposiciones conscientes e inconscientes. Desde mi perspectiva, esta noción de singularidad es histórica contexto-dependiente y formada dialécticamente a modo de configuración cultural-, a la vez que se incrusta también en el cuerpo, a modo de disposiciones duraderas y na- turalizadas: como habitus, en los términos de Bourdieu (2011).

Ricouer (2006) es perspicaz al darse cuenta de que este proceso de identificación de la singularidad no puede "ser por sí mismo". Él requiere de otra dimensión comparativa sine qua non, sin la cual ninguna singularidad pudiera emerger. La experiencia de identificación de la singularidad demanda que el "yo" pueda reafirmar la factibili-

26 Esto es particularmente atingente cuando observamos, por ejemplo, la composición de las identidades peruana y chilena en Arica. La presión del Estado chileno por construir una adscripción identitaria chilenizada se ha dejado sentir como una política violenta aplicada localmente por más de medio siglo. Pero, más allá de la intensidad y violencia de esta operación estatal, el control de personas y prácticas que pertenecen al espacio "chileno" y "chilenizado" no ha logrado cumplirse en cuanto coherencia social tácita, deviniendo en incongruencias identitarias como mínimo curiosas. Entre nuestros entrevistados, por ejemplo, había chilenos que no conseguían describir claramente el origen nacional de su familia, dada la reciente y compleja asignación de la frontera. Lo mismo pasaba entre nuestros entrevistados peruanos. También lo observábamos en la naturalidad con que la gente chilena entendía la comida peruana como "la comida que se come en Arica", asumiendo como propiamente chilenos ciertos gustos, formas de consumo y de preparación de los alimentos que, en el centro de Chile, serían consideradas "culturas peruanas".

27 El argumento de Ricouer (2006: iv) sobre las identidades coincide parcialmente con el debate de Anderson (1993: 63-76) sobre la formación de la conciencia nacional. Para ambos la emergencia y difusión de un proceso narrativo sobre la identidad compartida dan forma a la conciencia sobre esta identidad. La repetición discursiva a través del texto, según sus reflexiones, tendría el efecto de historizar tanto las identidades como la consciencia colectiva. Heidegger (2004: 43) establece una relación parecida entre la constitución de la subjetividad, del ser y de su inmanencia histórica cuando asume que el lenguaje es "la casa del ser" y que sólo habitando el lenguaje el ser puede existir y tomar consciencia de su existencia y de aquello que en ella se repite temporalmente. Aunque esté de acuerdo con el papel que el lenguaje y el discurso escritos desempeñan en la construcción de la conciencia sobre las identidades, considero que estos argumentos marginan el papel de las prácticas performáticas -o incluso de la literatura oral (Hastings 2000: 38)- en el desarrollo de las identidades nacionales, étnicas, o comunitarias. Es necesario complementar el argumento sobre el papel del discurso, lenguaje y narración en la emergencia de la conciencia identitaria con una reflexión sobre el rol jugado por las prácticas corporales (tema que retomaré en las consideraciones finales). 
dad de su singularidad haciéndola materializable en un "otro" considerado igual. La singularidad de la identidad dependería, entonces, de su coexistencia con su antítesis: la semejanza con un algo (o alguien) igual. La noción del "yo" implicaría un proceso centralmente dialéctico, en el que el sujeto (ya sea individual o colectivo) se compara en cuanto singularidad, a la vez que asume y se deja interpelar por la semejanza hacia un "igual". Al hacerlo, el sujeto se convierte en un "sí mismo como otro" (Clavel et al. 1998: 152).

Empiezo este apartado con esta reflexión porque ella me permitirá fundamentar la forma como la experiencia de un "yo" transnacional por parte de las migrantes peruanas con las que conviví, se articuló, en mi estudio de caso, con un proceso de reflexividad antropológica. Me refiero a que mi "yo" también ha devenido parte de estas relaciones dialécticas entre las identidades de las mujeres, su entorno y nuestros procesos de inserción social en una zona donde las fronteras entre el ser y el no ser son visiblemente inestables ${ }^{28}$. Mi lugar en estos procesos dialécticos de la identidad ha sido inesperado, contradiciendo todo aquello que, en un primer momento, había previsto.

Al empezar el trabajo de terreno en Arica, formé un equipo compuesto por tres estudiantes de antropología ( $\mathrm{Fe}$ lipe Valdebenito, Grecia Dávila y Orlando Heredia) y por una socióloga (Arlene Muñoz). Yo era la única extranjera de este equipo y esto era intencionado. Esta conformación interpelaba mis prejuicios sobre la forma como las mujeres migrantes peruanas me interpretarían en los espacios sociales en los que actúan o por las que transitan en Arica. Desde mis primeros momentos en la ciudad he sentido una tensión constante en relación a mi diferencia fenotípica. Diariamente me preguntaban sobre mi origen nacional, casi siempre asumiendo que yo fuera europea o norteamericana debido al color blanco de mi piel, a los ojos claros y al pelo rubio.

28 La inestabilidad de las diferencias entre "los chilenos" y sus "otros" en esta zona fronteriza es activada a través de procesos reiterados de enunciación de las diferencias. Estos procesos tienen por finalidad establecer - con buena dosis de violencia- la regularidad y permanencia de unas identidades que, en las prácticas cotidianas, son más confusas y más volátiles de lo que se pretende desde el ámbito nacional y estatal chileno.
Lo que en un primer momento me parecía un proceso de curiosidad hacia la diferencia, luego pasó a sentirse como un proceso constante de etiquetaje y narración sobre mi inadecuación al contexto local. Juntamente a las consideraciones sobre mi diferencia fenotípica, se me preguntaba reincidentemente sobre cuánto tiempo más pretendía quedarme en Arica y sobre por qué no me devolvía a mí país. Mi malestar con estas interpelaciones sólo empezó a quedarme del todo claro cuando observé, revisando mis diarios de campo, que ellas se repetían por lo menos tres veces al día, en espacios diversos, incluso en aquellos ámbitos de la universidad donde me había incorporado como miembro de un equipo de investigadores con amplia experiencia internacional. Era difícil no sentir estas interpelaciones como un proceso colectivo de enunciación de mi inadecuación: ellas eran un aviso diario, narrativo e reincidente sobre mi condición de extranjera. Estos etiquetajes permitían observar, en el discurso e interacción de la gente hacía mí, unas representaciones más o menos generalizadas acerca de cómo se vinculaban ciertos estereotipos fenotípicos, de formas de ser, de hablar y de carácter a ciertas nacionalidades. Observé que estas representaciones sobre unas y otras nacionalidades se repetían en el discurso de personas de diferentes sectores sociales. Mi condición de extranjera parecía, en este sentido, estimular la enunciación de estas representaciones, puesto que el primer tema de las conversaciones conmigo estaba siempre vinculado a esta condición. En relación a mi nacionalidad brasileña, por ejemplo, emergía una y otra vez la consideración de que yo "no podría ser de Brasil", ya que los brasileños "son morenos o negros".

Además de permitirme montarme un curioso mapa mental sobre cómo gentes de diferentes edades, géneros y clases sociales en Arica relacionaban similarmente ciertos fenotipos y ciertas nacionalidades, esta experiencia de alteridad me condujo a una constatación centralmente importante para un estudio sobre la migración en zonas fronterizas. Ésta se refiere a que, a diferencia de mi experiencia en otros lugares de Chile (como Valparaíso) donde había residido antes, la identificación y delimitación de la diferencia nacional de la gente $-y$, no menos, el ser capaces de apuntarla de forma tajante a partir de características externalizables, como los rasgos fenotípicos- constituía un ejercicio cotidiano de la gente chilena que reside en la ciudad. La repetición agotadora de las 
mismas preguntas sobre mi condición extranjera en los diferentes espacios no era casual. Mi hipótesis es que la insistencia de estos etiquetajes en las relaciones cotidianas es un resquicio potente de los procesos estatales de chilenización de estos territorios del norte de Chile. Son parte de un imperativo de identificación de unos y otros que opera en las prácticas sociales cotidianas, convirtiéndose en el modo sine qua non a partir del cual los sujetos interpelan todo aquello que no constituya el ideal autorrepresentativo y fenotípico de lo local (o, mejor dicho, de lo "chilenamente local").

En este sentido, la formación de un equipo compuesto mayoritariamente por personas de nacionalidad chilena, de diferentes clases sociales y provenientes del norte del país buscó evitar que mi condición de extranjera y mi "apariencia gringa" (como me decían una y otra vez) fueran sentidas por las mujeres peruanas como una distancia de otredad insalvable, que les inhibiera al diálogo. En otras palabras, partiendo del prejuicio de que las mujeres peruanas en Arica (al igual que los locales) me entenderían como un ser ajeno, formé el equipo destinado a superar la sensación de extrañeza que la gente del entorno sentía sobre mi diferencia, buscando personas que, conocedoras del espacio local, pudieran entablar un mejor diálogo con las mujeres ${ }^{29}$.

Pero nuestras experiencias etnográficas como equipo en terreno han derribado la ingenuidad de mis planteamientos iniciales sobre la forma como mi persona sería interpretada e interpelada por las migrantes peruanas. En la medida en que empezamos a frecuentar y a hacernos presentes en los espacios de la migración peruana en Arica -el Terminal Internacional de Buses, el Agromercado, los campamentos, las hospederías del barrio Juan Noé y los comedores de la Iglesia católica - se hizo patente la dificultad de mis co-investigadores chilenos en establecer un diálogo en confianza con los y las migrantes.

Lo primero que identificamos en estos espacios se refería a la forma cómo hombres y mujeres estaban divididos

29 Aunque en el momento no lo pude percibir racionalmente, mi sensación de inadecuación me produjo cambios corporales que sólo he podido racionalizar del todo meses después de haber terminado mi proceso intensivo de terreno en Arica, y meses después de haberme cambiado de la ciudad.
(Guizardi et al. 2014). En los locales como el terminal de buses, donde los migrantes se disponen para ofrecer su mano de obra para el trabajo por día ("a jornal"), mujeres y hombres peruanos están físicamente separados. Las parejas, por ejemplo, aun cuando llegaban juntas al local, se despedían en la esquina para que el hombre fuera a juntarse con otros migrantes, y la mujer con el grupo femenino. Lo mismo ocurría también en las mesas de los comedores sociales de la Iglesia católica y en los espacios comunes de las hospederías de migrantes. En el Agromercado las relaciones entre géneros eran más fluidas, dada la complementariedad económica de las funciones desarrolladas por hombres y mujeres migrantes en el marco de la cadena productiva de este mercado. Aun así, los espacios y funciones femeninos y masculinos estaban claramente delimitados: el que las funciones productivas requirieran el diálogo y la interacción entre géneros no quitaba que cada uno de los géneros tuviera sus lugares y nichos laborales específicos y/o predominantes. Observando la persistencia de esta separación por géneros en el espacio, nos hemos separado como equipo etnográfico: los dos investigadores actuaban en los espacios masculinos, y las tres investigadoras en los espacios femeninos. En ambos, hombres y mujeres peruanas se mostraban reacios a conversar con mis co-investigadores chilenos.

Orlando Heredia sólo fue aceptado en los espacios masculinos alrededor del Terminal Internacional tras haber pasado varios meses acudiendo diariamente a ellos y siendo, sistemáticamente, ignorado por los migrantes. $\mathrm{Su}$ aceptación se dio cuando, tras haber entrevistado individualmente a casi todos los migrantes que estaban habitualmente en el local -lo que hizo de forma gradual, visitando las hospederías donde se alojaban por la noche-finalmente le invitaron a tomar un café peruano. Felipe Valdebenito tuvo algo más de suerte en su etnografía del Agromercado. Logró establecer contactos más cercanos ya en el segundo mes de investigación, debido a que era figura habitual del mercado: su familia está involucrada en la distribución de productos agrícolas y Felipe trabajaba en el recinto, en el rubro de camiones de su padre. Pero incluso a él, quien trabajaba a diario con hombres y mujeres migrantes, le costó acceder a diálogos horizontales con la gente.

Arlene Muñoz, a su vez, enfrentó una resistencia similar por parte de las mujeres migrantes peruanas en los co- 
medores sociales a los que acudía de cuatro a cinco veces por semana. Sólo logró conversar con las migrantes de forma más horizontal tras muchos meses de presencia en los comedores; y esto tras haber acordado aceptar, tácitamente, todas las condiciones que estas mujeres le indicaban: que lo que dijeran no llegara a los oídos de la administración de los comedores; que las entrevistas se tomaran fuera del comedor y que Arlene seguiría haciendo como si no las conociera. Por otra parte, las mujeres chilenas que acudían al comedor para cenar y también aquellas que trabajan como voluntarias en el local -organizando y limpiando el espacio, preparando las comidas y sirviendo a la gente- aceptaron a Arlene rápidamente como una interlocutora, lo que no hizo más que entrabar la cercanía hacia las migrantes peruanas.

Grecia Dávila, quien etnografió los espacios femeninos del Agromercado, en más de una ocasión fue desautorizada por las mujeres peruanas y bolivianas a estar cerca de sus puestos de venta, conversar con ellas o entrevistarles. Su contacto con las mujeres sólo se pudo ir construyendo tras casi dos meses en terreno, y ocurrió en la medida en que pasó a visitar conmigo los campamentos donde buena parte de ellas residían. Esto nos permitió a ambas acceder a sus espacios de vivienda, compartir con ellas el té y, gracias a esto, entablar otras formas de diálogo en la que podríamos presentarnos de forma más cercana. Esta "forma más cercana" es un eufemismo para designar el que, al visitarlas en sus viviendas, llegáramos a compartir con estas mujeres problemas y diálogos que ellas entendían como femeninos: hablábamos de las relaciones de género, escuchábamos los casos de violencia y de violaciones, hablábamos sobre salud reproductiva, sobre cómo matricular los niños y niñas indocumentados en los colegios ${ }^{30}$.

Las dificultades enfrentadas por Arlene, Grecia, Felipe y Orlando contrastaban fuertemente con la facilidad con que yo había circulado por todos los espacios femeninos donde mis co-investigadores realizaban sus etnografías. Aunque yo también estuviera sujeta a las delimitaciones que mi condición de género implicaba -no podía estar y circular por los espacios entendidos como "masculinos" por los migrantes- me resultaba del todo más cercana la relación con las mujeres peruanas tanto en los campamentos, como en el Agromercado, en el terminal de buses y en los espacios aledaños a éste.
El primero de los espacios migrantes de Arica que frecuenté - desde noviembre de 2012- fue el Terminal Internacional. Había llegado a vivir a la ciudad desde hacía pocos meses. Para conocer a la gente migrante, decidí pasar las mañanas y tardes sentada en el local que me parecía un punto obligado para los y las peruanas que llegaban a la ciudad: el patio del terminal desde donde salen y llegan los buses que conectan Arica a Tacna. Allí, sentada a lo largo de varias horas diarias en un muro de media altura donde la gente se apoyaba esperando al bus, conversé, desde el primer día, con mujeres peruanas y bolivianas. Y también con hombres de estas dos nacionalidades ${ }^{31}$.

Fue una señora peruana la primera en abordarme, unos quince minutos después que yo me hubiera sentado en este local. Me preguntó si le podría ayudar tomando su hija en brazos mientras ella preparaba a la niña algo de comer. Llevaba la pequeña de vuelta a Tacna donde se quedaba a los cuidados de su hermana mayor, mientras ella trabajaba como empleada doméstica en una casa ariqueña. Le acompañé hasta que su bus saliera, y mientras conversaba con ella -preguntándole sobre cómo era la

30 Nuestras visitas a las casas de las migrantes en los campamentos Areneros y Coraceros se daba por las noches, cuando éstas regresaban de su jornada de trabajo. Las conversas y las dudas que surgían por parte de estas mujeres nos impelían a buscar solución o respuestas para los problemas y cuestiones planteados. Junto con las mujeres, y observando la generalización de ciertas dudas sobre los derechos de salud, documentales y de educación de los migrantes y sus hijos en Chile, realizamos una serie de talleres informativos en los campamentos. Invitamos a dos abogados expertos en materias migratorias, Katherine Navarro y Tomás Greene, a que nos acompañaran en estas instancias informándonos y aclarándonos las dudas que entre todas teníamos. Estos talleres fueron realizados a inicios de 2013 y acontecían en la casa de una de las mujeres migrantes del campamento Areneros (que disponía de un pequeño generador, permitiéndonos realizar las charlas con algo de luz eléctrica).

31 Mi posibilidad de hablar con los hombres se dio por el hecho de que aquel pequeño muro representaba uno de los pocos espacios mixtos del terminal: donde hombres y mujeres pueden estar indistintamente y donde podrían dialogar e interactuar. El pequeño muro separaba el patio del terminal de las dos casetas de baño masculino y femenino. Quizás por tratarse de un espacio de tránsito y espera de hombres y mujeres para el uso de los aseos y duchas, es que se generaba cierta permisividad de diálogos y contactos entre géneros. 
experiencia de tener hijas $y$, sobre todo, de tenerlas entre dos ciudades-, otras mujeres peruanas también sentadas en el muro se integraron a la conversa, hablándonos como ellas también vivían estas circunstancias y cómo solucionaban las dificultades de una vida familiar de este tipo. Este fue mi primer acercamiento a la realidad transfronteriza de las madres peruanas que trabajan en Arica: y lo hice con una bebé en brazos, imaginándome cómo sería mi vida si estuviera en el lugar de estas mujeres.

Pero, y de esto solo pude tomar conciencia muchos días más tarde, las mujeres me interpelaban en una misma medida, sino más, que yo a ellas. La señora a quien le cuidé a la niña me preguntó si yo tenía hijos. Al recibir la respuesta negativa, me indagó porqué no. De a poco, me fue interrogando sobre mi vida de pareja, sobre la nacionalidad de mi pareja, sobre si ya había conseguido legalizar mis documentos en Chile, y sobre cómo me trataban los chilenos en la ciudad y en mi local de trabajo. Lo curioso de esta conversa fue que ella resultó en la primera entrevista en profundidad de mi etnografía, y la persona entrevistada no fue la señora peruana que - para usar jerga antropológica - era el "sujeto prioritario de mi investigación". La primera entrevista en profundidad del estudio, me la hizo una señora peruana a mí, y me preguntó todas las cosas que yo pretendía saber sobre ella. En la medida en que le iba contestando, las señoras sentadas al lado también iban dando sus opiniones, haciéndome preguntas complementarias. Y, gracias a sus comentarios y consejos sobre la cuestión documental, me fui dando cuenta de que ellas me podrían ayudar mucho más de lo que había previsto. Les pedí su autorización para tomarme notas de los datos que me daban sobre la legalización de mis documentos migratorios: sobre los lugares donde ir, y sobre qué procedimientos hacer. Así, los primeros registros de mi diario de campo son apuntes sobre cómo solucionar mis problemas migratorios en Chile, lo que no exactamente cualifica como una descripción densa acerca de mis sujetos de estudio.

Esta conversa fue sucedida por muchas otras con mujeres peruanas de diferentes partes del Perú. Una y otra vez, las mujeres me comentaban e indagaban sobre mi vida, y nuestra conversa siempre partía de sus preguntas sobre mi condición migratoria en Chile. A partir de mis respuestas, contaban sus propias historias de migración y de vida transfronteriza, pero en muy pocas ocasiones fui yo quien inició el tema. Además, muchos de lo que ellas me preguntaban ni siquiera había figurado en $\mathrm{mi}$ imaginación como un tema relevante. De a poco, ellas me fueron dando pautas sobre cómo se estructuraban sus preocupaciones, sus acciones y sus miedos. $Y$ sus pautas me llevaron a la atención de mis propias preocupaciones, acciones y miedos en el marco de mi condición migratoria en Arica.

En estos interminables días en el terminal, me impresionaba la diversidad de personas, de temas, conversas y visiones de mundos que me iban interpelando sin que yo saliera (físicamente) del lugar. Aunque en la primera mañana nadie me hubiera preguntado qué estaba haciendo allí -la gente parecía asumir que esperaba algún bus, mi presencia por la tarde llamó la atención de los choferes y de las mujeres que contrabandean ropa usada. Éstas adoptaron una actitud de indiferencia, mientras los primeros decidieron hacer una apuesta sobre las razones de mi insistencia. Uno de los choferes, en nombre del grupo que hacía la apuesta, vino a conversar conmigo imbuido de la tarea de descubrir qué hacía yo tantas horas sentada en la puerta del baño, conversando con la gente y tostándome bajo un sol que se hacía ya algo impetuoso en aquella altura del año. Y llegamos así a la segunda entrevista en profundidad de la investigación, en la que la persona entrevistada no fue Roberto, el chofer de la empresa peruana de buses. Una vez más, mi "sujeto de estudio" me entrevistó a mí.

Tras contarle la historia de mi vida hasta mi llegada a Arica, Roberto se convenció de que yo no era un agente de policía infiltrado y, tras constatar haber perdido su apuesta, me hizo el franco favor de contarle a sus compañeros sobre mi estudio y sobre las razones de mi presencia. Nadie se ganó la apuesta. Al día siguiente, las señoras del tráfico de ropa-quienes trabajan en íntima colaboración con los choferes de buses- ya sabían mi historia, con lo que dejaron de mostrarse indiferentes. Algunas de ellas, sabiendo que yo no saldría de mi puesto en el muro, me pasaron a pedir que vigilara sus grandes bolsos, mientras iban a los galpones del cercano barrio de Juan Noé buscar más ropa usada para embarcarla a Tacna. Me fue imposible registrar todas las conversas que este segundo día de terreno me ofreció en el terminal. Pero recuerdo haber terminado el día con la extraña sensación de haber narrado mi vida más veces de las que podía cuantificar. En este espacio 
nadie me preguntaba cuándo yo me volvería a mi país. También era divertido constatar que, para las mujeres peruanas, no les resultaba extraño que una brasileña fuera blanca y rubia. Algunas me decían que "Brasil es como Perú, tiene de todo". Otras, más directamente, me contaban que habían visto muchas telenovelas brasileñas, y que en ellas salían muchas mujeres blancas ${ }^{32}$. Me sorprendía percibir que, a diferencia de lo que me pasaba con la gente chilena en Arica, mi fenotipo despertaba confianza por parte de las mujeres peruanas. Y la respuesta del porque era igualmente interesante: "se ve que no eres chilena, pues'". Unos y otros me etiquetaban por mi fenotipo, asociándolo a la condición de extranjera en Chile. Pero mientras para los chilenos esto hacía de mí un sujeto con intenciones dudosas; para las peruanas esto me convertía en alguien en quien confiar.

Cuando hablo de confianza, me refiero a escenas y situaciones en las que se depositaban en mí responsabilidades no menores. En el segundo día de mi terreno, conocí a una señora peruana que viajaba con cuatro hijos (dos niños y dos niñas). El niño mayor, nacido en Chile y de once años, había olvidado su carné de identidad en casa, en Santiago, y no podría cruzar la frontera hacia Perú así indocumentado. La señora no disponía de recursos para devolverse a buscar el documento, lo que implicaría pagar cinco pasajes más. La escuché discutiendo con el hijo y consensuando con él sobre qué hacer. La única solución económicamente viable era que el chico se devolviera solo a Santiago: su padre le recogería allá y lo llevaría a casa. Habría que hacerle una autorización legal en la policía, pero la madre se negaba a dejarlo solo en el terminal hasta el horario de su bus. Desorientada, ella se sentó a mi lado en el muro, llorando. Estuvimos conversando por casi dos horas y le dije que yo podría cuidarle hasta que

32 Es cierto que las telenovelas brasileñas, exportadas como producto mediático global, han tenido un importante papel en la divulgación de unos estereotipos sobre el color blanco de la piel asociado sobre todo a los sectores más pudientes de la sociedad, a los que estas novelas representan comúnmente. Pero de por sí, el consumo de este tipo de producto televisivo no explicaría el imaginario de diversidad que las peruanas llegan a tener acerca de Brasil en comparación con el imaginario chileno, que asume la negritud como distintivo del "ser brasileño". Especialmente si observamos que el consumo de telenovelas brasileñas en Chile es tanto o más generalizado que en Perú. su bus saliera, que yo me quedaría con él en el terminal. Y fue así como la señora me entregó a su hijo, de quién me hice cargo toda la mañana y tarde, hasta que le embarqué en su transporte de vuelta a su casa. Cuando el pequeño embarcó, llamé al padre del niño en Santiago y también a la madre en el Perú. Esta historia circuló de forma insospechada entre las mujeres peruanas en el terminal, quienes mucho tiempo después me seguían preguntando si yo era la brasileña que había cuidado al niño de Santiago.

Un día, otro día y otro día más sentada en el muro me fueron dando también una dimensión de las dinámicas circulares del espacio del terminal y de la vida transfronteriza: de las mujeres que iban y venían siempre ciertos días de la semana; de las señoras que contrabandeaban ropa usada de Chile a Perú en sus hasta seis cruces diarios de frontera - que contaba a partir de las veces que las veía subir y bajar de buses en un solo día-. Con el paso de las semanas, al seguirme encontrando con las mujeres que circulaban por aquel espacio en días puntuales, también ellas se fueron interesando por mi presencia, y ya no era una novedad mi trabajo de campo etnográfico. Pero lo que les importaba era más bien mi historia: me preguntaban cada semana sobre mis trámites documentales, sobre los problemas burocráticos que tenía con $\mathrm{mi}$ contrato laboral y sobre las dificultades de mi experiencia personal. De a poco, estas mujeres me fueron invitando a sus casas, a conocer los cuartos que compartían con otras mujeres peruanas en la población Juan Noé. Y tomando once con ellas algunas veces de la semana, en sus casas, me contaron sobre sus vidas, me presentaron otras mujeres y me aguacharon en sus redes.

Experiencias muy similares a esta del terminal se repitieron en los campamentos de Arica, y en las hospederías para migrantes (espacios que yo visitaba por las noches alternadamente). Mi sensación de acogimiento por parte de las mujeres peruanas que yo conocía contrastaba terriblemente con la experiencia de tensión que resultaba de mis relaciones con chilenos y chilenas en la ciudad.

Estas circunstancias, más allá del mero cliché etnográfico - de una antropóloga que quizás ingenuamente se siente reconocida a través de sus sujetos de estudio-impactan singularmente la forma como he llegado a teorizar la simultaneidad transnacional en el marco de la experiencia de las migrantes peruanas en Arica. 
En primer lugar, porque, a contracorriente de lo que yo suponía al inicio del trabajo, mi condición de extranjera, de migrante en Arica, implicaba una semejanza percibida por parte de las mujeres peruanas que positivaba las diferencias fenotípicas que, para las personas chilenas con las que convivía, eran determinantes inamovibles de mi distancia en relación a ellas. Pero, por otro lado, la relativa facilidad con la que fui estableciendo contacto con estas mujeres - a diferencia de lo que pasó con mis co-investigadores- se debía, centralmente, al hecho de que ellas identificaban en mi trayectoria migrante la experiencia de unas dificultades que ellas también enfrentaban ${ }^{33}$. En efecto, yo era alguien que enfrentaba un proceso de alteridad semejante al suyo. Ellas me fueron permitiendo entender la forma como asumían este proceso estratégicamente, impactando las maneras de pensar y vivir la conformación de su "yo". Esto se refería, fundamentalmente, al desarrollo de habilidades que, más o menos conscientes, impactaban y marcaban el cuerpo de estas mujeres. Su experiencia de migrantes peruanas viviendo de un lado y de otro de la frontera chilena demandaba de ellas el desarrollo de capacidades de conformación del "yo" que constituían recursos sine qua non para producir y reproducir la experiencia transfronteriza.

La primera de estas habilidades decía relación con la capacidad de entrar y salir de la posición del "otro". Me refiero a que las mujeres iban desarrollando, paulatinamente, la habilidad de transitar de la relación entre "otros y unos" proyectada por los chilenos hacia ellas, y la relación entre "otros y unos" que ellas mismas proyectaban hacia los chilenos. Esto no es del todo novedoso: es algo que se verifica en la experiencia migrante en diferentes contextos sociales y nacionales. Pero lo que llamaba mi atención en el caso de las peruanas se refería a que ellas transitaban de una condición a la otra varias veces al día y, a veces, en el marco de una misma situación. Y lo hacían también en sus procesos de comunicación con los espacios de origen que, en el caso de Arica, no son solamente virtuales, sino que derivados del desplazamiento físico: las mujeres viajan al Perú semanalmente y, en algunos casos, varias veces por semana.

A partir del momento en que comprendí esto, pasé a recopilar en los relatos de las mujeres aquellas escenas y narraciones sobre situaciones sociales en las que asumían el lugar de otredad y las tensiones de esta identificación como forma de cumplir, estratégicamente, con las demandas identitarias posicionadas por el "otro".

Por ejemplo, durante las mañanas, las mujeres peruanas que trabajan por el sueldo diario esperan a los contratantes chilenos sentadas en las esquinas del Terminal Internacional. Les vienen a ofrecer servicio normalmente hombres que llegan caminando, tras estacionar su coche en las calles colindantes. Muy a menudo el trato por parte de estos contratantes es agresivo para con las mujeres, preguntando por ejemplo si se duchan o cepillan los dientes; y rechazando aquellas a las que consideran "sucias". Con las mujeres indígenas, el trato suele ser más duro, y en reiteradas ocasiones escuché de los contratantes interpelaciones del tipo: "habla bien india, ino sabes hablar castellano?".

Cuando uno de estos hombres llega, las mujeres corren a su alrededor para negociar el trabajo -en el servicio doméstico, en la cocina de restaurantes, en pequeñas empresas de empaquetado, e incluso en el sector textil-34. Su forma de hablarles a estos contratantes es siempre muy sumisa: no les miran a los ojos, les hablan en voz baja y, si el sueldo ofrecido es considerado injusto, no lo enuncian abiertamente. Se esquivan de la conversa dejando que la oferta sea aceptada por las mujeres que la consideren aceptable. Al indagarles sobre la práctica, sentada con ellas en la esquina del terminal, me comentaron que los contratantes eran unos estúpidos, que esperaban de ellas que fueran dóciles; y que mientras les dieran trabajo, ellas podían adecuarse a esta imagen (inexacta)

33 En gran medida, mi delicada condición documental y mis dificultades laborales como extranjera en Arica emergían en el discurso de las peruanas como elementos que hacían de mí una igual. Estos aspectos de mi propia experiencia social en el norte de Chile me fueron subrayados por las migrantes: su interpelación constante no solamente me hacía racionalizar circunstancias que aún no había llegado a percibir del todo. Las mismas mujeres me hicieron ver que la tensión que yo sentía sobre mi diferencia, no era exactamente algo que se debía a mi diferencia específica. Ellas también sentían, y con mucha más violencia, este ejercicio clasificador constante en las relaciones con los y las chilenas.

34 El trabajo agrícola es la última opción: ellas lo describen como peor pagado que las labores urbanas y bastante más exigente físicamente. Es desarrollado en condiciones frecuentemente insalubres: bajo sol fuerte, con poca agua, sin espacios de descanso, y por muchas horas seguidas. 
que tenían de ellas. A partir de esta silenciosa caminata hacia atrás, las mujeres personificaban su derecho de rechazar las condiciones de trabajo - un acto de elección en el que reside cierto grado de potestad y de agencia-, pero sin romper en la relación con el contratante la sumisión que éste proyectaba en ellas. A medio camino entre resistencia y sumisión, las mujeres entraban y salían, en una única escena, de la relación de otredad y diferencia constituida con el otro chileno.

Al indagarles sobre esta capacidad de adecuarse y desadecuarse - de codificar y decodificar- miles de otras escenas iban surgiendo en sus relatos. Muchas de ellas referentes al ambiente laboral, reincidiendo en lo necesario de esta flexibilidad en la relación con los locales. Las mujeres dialogan sobre estas estrategias entre sí, especialmente en estos espacios prioritarios femeninos de espera por trabajo. En estas conversaciones, constatamos cómo ellas interpretan su contacto con los autóctonos, sobre las diferencias de perspectivas y sobre su reconocimiento de los mecanismos de explotación a los que están sujetas. Genny nos contó, por ejemplo, que "la gente chilena les acuchillaba por las espaldas", las ponían a trabajar muchas horas. Delante de ellos decían "que bien, todo bien". Pero a sus espaldas decían "que las peruanas no trabajan bien, son flojas, no sirven, no hacen bien". Y, sigue Genny, "las peruanas se asustan por la manera como las chilenas hacen las cosas de cocina":

"Yo trabajé en restaurantes chilenos aquí, cortando papa, cortando verdura, lavando plato. Las cocineras chilenas no lavan las verduras: nos dicen de cortar, y cuando cortamos, las cocinan así mismo, sin lavarlas. Yo trabajé aquí en el restaurante X [omitimos el nombre], y ahí la cocinera es peruana, que allí sí la comida es limpiecita, limpiecita que ella nos hace lavar las verduras dos, tres veces antes de cortarla, que hay que lavar las lozas muy bien, bien". (Genny, Diario de Campo. Diciembre de 2012).

A través de los relatos de Genny vemos muy claramente la conformación de un discurso esencializador sobre el "ser" de las peruanas y el "ser" de las chilenas, y que es radicalmente diferente del discurso autóctono (igualmente esencializador) sobre las diferencias entre estas identidades nacionales. Más allá de las limitaciones esencialistas de una y otra de estas visiones, las peruanas habían desarrollado maneras de autocumplir el ideal esencializador de la mirada chilena hacia ellas, sin con ello abandonar la construcción de un arquetipo identitario propio. Lo llamativo era justamente esto: la capacidad social y psicológica de experimentar formas asimétricas de configuración del "yo", transitando entre ellas sin padecer de la incoherencia de personalidad que de este tránsito pudiera derivar.

Este tipo de habilidades demandaba de las mujeres ciertas alteraciones corporales: en la forma de peinarse, en la forma de vestirse, de hablar, de mirar, de caminar y de comer. Les inculcaba ciertas capacidades de performance del "yo" que variaban desde mínimos cambios en la forma de hablar, hasta cambios más complejos y cuidadosamente planificados en la apariencia física. Ejemplo de lo último es la adecuación que vivían las mujeres al momento de cruzar la frontera. La necesidad de personificar estos cambios planificados de la apariencia se refería a que la Región de Arica y Parinacota contaba (hasta julio de 2013) con una legislación propia sobre la circulación de personas de nacionalidad peruana. Regía un tratado conocido como "el acuerdo de los siete días"35, según el cual los migrantes peruanos podrían entrar a la región sin visa turística y sin visa para residencia ${ }^{36}$.

Al cruzar Chacalluta -el control fronterizo del lado chileno- los peruanos recibían un documento denominado "Salvoconducto", con el que supuestamente podrían circular y hacer turismo en la región de Arica y Parinacota,

35 El Convenio de Tránsito de Personas en la Zona Fronteriza Chileno-Peruana de Arica-Tacna, más conocido como Convenio Arica-Tacna, constituía una norma específica para el ingreso a Chile que sólo aplicaba dentro de los límites de la Región de Arica y Parinacota. Fue suscrito en Lima el 13 de diciembre de 1930, promulgado en Chile el 20 de febrero de 1931 (a través del Decreto 174), y publicado en el Diario Oficial 15.923 el 14 de marzo de 1931. No obstante, fue puesto en vigor en Chile en 1983 (Tapia y Ramos 2013). Desde julio de 2013, sin embargo, el Gobierno chileno suspendió la aplicación del Convenio, aplicando el criterio de que todos los peruanos que crucen a Arica y Parinacota deben cumplir con los requisitos de solicitud de una visa turística.

36 El Convenio permitía una cierta flexibilidad y maleabilidad fronteriza entre estas regiones chilenas y peruanas, permitiendo la mantención de la dinámica económica compartida que Tacna y Arica han tenido históricamente, e instituyendo entre ambas un régimen de flujos que no opera en un mismo sentido/intensidad entre otras regiones de Chile y Perú. 
pero que no les habilitaba para el trabajo o para cualquier otra función remunerada. Con este documento, tampoco podían cruzar la frontera sur de la región. En la Aduana chilena de Cuya (entre las regiones de Arica y Parinacota y Tarapacá), los peruanos tenían que presentar una visa turística, o bien la visa de residencia (temporaria o permanente), sin las cuales no podían acceder a las regiones más al sur, donde se encuentran las industrias mineras más importantes de Chile. Esto provocaba una fuerte división entre el perfil de los migrantes peruanos que se dirigían a Arica, y aquellos que se dirigían a ciudades como Iquique y Antofagasta. Esta división se refería, por un lado, a la cantidad de capital económico, y la especificidad del capital social y cultural que los migrantes acumulaban previamente a su desplazamiento hacia Chile. Para conseguir una visa de turismo, peruanos y peruanas necesitan antes contar con un pasaporte de su país, un trámite burocrático que implica ahorrar un considerable valor monetario. Se trata así de un proceso que usualmente no está al alcance de los trabajadores rurales, o de los trabajadores informales urbanos del sur del país dado el perfil de renta y la baja capacidad de acumulación económica de estos trabajadores-. El trámite requiere, a la vez, una cierta capacidad de conocer el funcionamiento de los campos burocráticos chilenos y peruanos, un capital cultural sobre cómo dialogar con los funcionarios de los dos Estados, sobre cómo tramitar los documentos, y, especialmente, sobre cómo presentarse en la frontera para cruzarla como turista. Consecuentemente, tramitar un pasaporte peruano y conseguirse la visa turística en Chile requiere una serie de conocimientos jurídicos, documentales, discursivos e incluso performáticos que dependen de redes sociales con migrantes que ya han vivido la experiencia. Junto con el pasaporte, para entrar como turistas, los peruanos deben contar con una bolsa de viaje que varía de los 500 a los 1500 dólares, lo que tampoco es factible para los trabajadores de las clases más bajas.

Las mujeres peruanas me contaban que era muy difícil entrar como turistas en Arica, incluso contando con el pasaporte y con la bolsa de viaje. De las 42 personas peruanas que entrevistamos solamente un hombre pudo entrar como turista en Chile en su primer intento ${ }^{37}$. Los demás han tardado entre dos y cinco años en conseguir la visa turística: algunos cruzando la frontera con pasaporte en mano aproximadamente una vez por semana durante por lo menos un año. Las mujeres me relataron que hay señoras que trabajan vendiendo sus servicios a peruanas que quieren entrar como turistas, enseñándoles exactamente cómo vestirse, qué hablar, y qué llevar a la hora de encontrarse con el oficial de la frontera en Chile:

"Estuve dos años aquí [en Arica] en la ropa [contrabando de ropa usada] y saqué mi pasaporte y me fui pa' Santiago con mi hermana. Y me timbraron el pasaporte [...]. En esos años, sí, en esos años me conseguí con una señora que me prestara la bolsa de viaje, entraban con bolsa de viaje, no sé si has escuchado [...]. En que en esos años las excusas de la PDI [Policía de Investigaciones de Chile] era - ¿a qué vas?'. -'Soy comerciante', le dije. - 'iAh!', y me dijo: -'Y, ¿a dónde vas?'. -'A Iquique', le dije. -'¿Y a qué?'...Que ya nosotras, todo estaba planificado ya: -'Voy a comprar unas zapatillas', le dije. - ¿Qué zapatillas?'. 'Las Rebook, las Nike'... Tenías que aprenderte un libreto [...]. - 'Ya, cy cuánto lleva de plata?'. -'Yo llevo como mil dólares'. -'A ver', dijo. Y nosotras... -'No, no, ahí no más', dijo. Porque típico de los peruanos, que las comerciantes se meten [el dinero] ahí... Dentro del sostén. Entonces ya empezamos: -'No, ahí no más', dijo. Y aparte que la señora que nos prestó el dinero, porque esas también te llegan a prestar, te alquilan prácticamente esa cantidad por si te dice 'muéstrame' la PDI. Entonces [la señora nos] dijo 'van a ir como gente comerciante, van a ir con un bolsito nomás", "no van a ir con sus maletas porque todo es psicológico. A ver, como comerciante con una maletita, lo básico, incluso si les adentran [si revisan el equipaje] van a ver un calzoncito, una muda nomás porque van a estar dos días, tres días nomás' [...]. Estaba todo planeado, otra persona nos entró pa' acá las maletas [...]. Con los años que trabajé acá [en Arica] pues, sí llegué a Santiago. También tenía la dirección toda de donde tenía que llegar a Santiago. (Meche, peruana, 31 años. Enero de 2013).

37 Esta situación excepcional de haber conseguido una visa turística en el primer intento supuso a nuestro entrevistado un problema junto a los demás migrantes peruanos con los que trabajaba en un reconocido restaurant de Arica: "En el restaurant también era otro problema. [...] Porque los que trabajan allá son peruanos $[\ldots]$ En la cocina son a ver... son como 12 [...]. El jefe de cocina es peruano, pero son de provincia, algunos. Y como yo me he criado más en Lima me tenían cólera; envidia. ¿Por qué? Porque yo entré acá y me dieron visa de turismo, tres meses. 
A partir del relato de Meche, sacamos varios elementos clave para entender la dinámica documental, social y económica del cruce de fronteras Perú-Chile. En primer lugar, siendo una trabajadora informal en Perú, Meche tuvo que venirse a Arica, ahorrar dinero para, después de dos años entre Arica y Tacna con el salvoconducto, obtener el pasaporte y realizar un intento de viaje a Santiago. En segundo lugar, la experiencia en Arica fue lo que posibilitó no solamente el recurso económico, sino que también las redes sociales y el conocimiento sobre cómo realizar el cruce (en este caso, contratando una señora que le "alquilaba" los dólares y le entrenaba para presentarse en el control fronterizo chileno). En tercer lugar, podemos darnos cuenta de las incongruencias de la legislación de extranjería chilena, que no cuenta con una visa específica para extranjeros que cruzan el país para actividades comerciales puntuales. Ante la falta de una legislación migratoria adecuada y adaptada a la amplia variedad de funciones económicas que pudieran desarrollar los extranjeros en Chile, los comerciantes deben entrar con visa turística, un documento que en principio no debiera habilitar para el desarrollo de funciones económicas ${ }^{38}$. Las migrantes comprenden este punto "ambiguo" de la legislación chilena, y juegan con las posibilidades que esta situación les permite a la hora de cruzar el país.

En cuarto lugar, el relato nos permite observar la operación de unos patrones sui géneris de concesión de las visas en el control fronterizo. La visa turística es otorgada en la frontera por los oficiales chilenos de la Policía de Investigación (PDI), quienes son responsables por el control de entradas de extranjeros. Estos oficiales determinan, siguiendo criterios que no están de un todo explícitos en la legislación, quienes pueden o no entrar como turistas y cuánto tiempo de visa turística se le otorga a cada solicitante. El periodo máximo es de 90 días, pero se puede dar menos días si tienen duda sobre los propósitos del extranjero. Esto significa que además de cumplir todos los requisitos legales para la visa, el ciudadano peruano tiene también que convencer al funcionario de turno de que realmente cumple con las disposiciones, y que puede vivir hasta tres meses en Chile sin trabajar, o bien que entra para desarrollar actividades comerciales puntuales (como comprar zapatillas importadas en la Zona Franca de Iquique). Observamos en nuestra etnografía que la decisión por parte de las autoridades parece tomarse sobre criterios fenotípicos (esto relatan los entrevistados también), y que se aplican métodos "no racionalizados" y aparentemente aleatorios de selección.

En este sentido, convencer al oficial de turno es un paso crucial, que implica aprenderse formas de lenguaje (además de montarse un discurso fiable y sin contradicciones sobre las razones del viaje); vestirse de manera para ser identificado con los trabajadores urbanos (indígenas y campesinos parecen ser más frecuentemente rechazados); y moverse de manera de no transparentar miedo, incertidumbre o ansiedad. De esta manera, cruzar la frontera como turista requiere que las mujeres entrenen unas performances a ser escenificadas frente al otro chileno que atienda las expectativas selectivas de este otro.

Aquí, siguiendo el ejemplo de lo que relaté sobre las mujeres ofreciendo su trabajo en el terminal, las migrantes deben desarrollar una habilidad flexible de entrar y salir en formas de personificación que les permiten circular o retenerse en uno u otro espacio. En el caso del cruce de fronteras, no obstante, esta personificación es más intensa, más aguda, derivando en formas casi teatrales de estar en la relación con "el otro" (en este caso, el funcionario de Aduana). Todo esto implica que ellas logren convivir con la personificación de su "yo" en por lo menos dos registros simultáneos: el "yo" que satisface a las relaciones locales con los chilenos; y el "yo" que satisface sus propias relaciones con sus familias en origen y con sus redes sociales de la migración peruana en Arica.

Mientras que a ellos les habían dado de semana [salvoconducto] [...] Siete días y tenían que regresar a Tacna" (Miguel Ángel, peruano, 28 años. Diciembre de 2012).

38 Una revisión crítica sobre las actuales leyes migratorias en Chile excede el objetivo del presente texto. Sin embargo, nos resulta importante mencionar la dimensión anacrónica de la Ley de Extranjería chilena, desarrollada en el marco de la dictadura militar, y puesta en vigor a partir del Decreto Ley 1094/1975. Como comenta Jensen (2009: 106), "con la dictadura de Augusto Pinochet, se realizaron algunas modificaciones a aquella ley de migraciones [la primera existente en Chile, promulgada en 1850], estableciéndose en 1975 el decreto de ley no 1094 , conocido como La Ley de Extranjería, que se caracterizó principalmente por su orientación policial y de control, cuyo objetivo era evitar la entrada de 'elementos peligrosos o terroristas' que amenazaran la 'estabilidad nacional'”. 
CONSIDERACIONES FINALES. (RE) CONCEPTUALIZANDO EL "YO"

Las narraciones y escenas que describí en el apartado anterior son el sustrato del planteamiento de la tercera de las relaciones dialécticas de la simultaneidad transnacional. Ésta se refiere a la construcción del "yo" migrante como una experiencia reiteradamente marcada de mismidad $e$ ipseidad (Ricouer 2006), como detallaré a continuación. Esto equivale a decir que las migrantes logran realizar una adaptación de sus capitales al contexto de recepción -a medio camino entre dejarse contener por y superar a las restricciones estructurales- por que logran constituir sentidos pertinentes de acción (racional o no, consciente o no) que integran en la práctica cotidiana dos dimensiones de su "yo". Por un lado, construyen un sentido social referente a su experiencia como propias de un lugar, es decir, su experiencia como sujeto autóctono de cierto espacio social (incluso cuando esta autoctonía implica un lugar marginado en la distribución y jerarquización social). Por otro lado, desarrollan un sentido social referente a su experiencia como un "otro" del contexto de recepción. Este último remite, claro está, a la construcción de los procesos de alteridad nacional y a su materialización y cristalización en los contextos de emisión, tránsito y recepción del migrante.

Con esto me refiero a que la forma como será construida y vivida la otredad de la migrante peruana en el espacio local ariqueño, que es el caso que nos toca, dialoga con procesos de larga duración: la Guerra del Pacífico, el establecimiento tardío de las fronteras entre Chile y Perú, las ideologías identitarias de la chilenidad y de la chilenización del Norte Grande, por ejemplo. Estos procesos, en la medida en que conforman Arica en cuanto configuración cultural, operan una presión estructural hacia la asignación de las identidades de los otros y otras peruanas, quienes son narrados como sujetos externos: contrastan como un opuesto bipolar y negativo del paradigma étnico nacional (Segato 2007).

Los migrantes, en la experiencia cotidiana en la sociedad de recepción, transitan entre estas asignaciones autóctonas sobre su otredad, y sus propias asignaciones identitarias, configuradas de acuerdo a los contextos, experiencias y espacios sociales en los que vivieron y por donde transitaron. Sobre esto nos alertaban las migran- tes peruanas en Arica cuando nos contaban que, en espacios de concentración migratoria, los y las peruanas se diferenciaban de acuerdo con los espacios concretos de procedencia. Y esta diferenciación, como hemos notado, reproduce las jerarquías que estos espacios ocupan en el paradigma étnico peruano. No era lo mismo ser costeña, norteña o serrana. Y no era lo mismo ser serrana del sur o del norte del Perú.

La experiencia de ser "el otro" de la sociedad ariqueña y de, simultáneamente, ser asignado a un locus específico (y fuente de distinción y diferenciación) en la jerarquía de aquellos considerados "sus iguales" opera un proceso de tensión del yo que reviste cierta importancia. En los relatos de las mujeres peruanas sobre su adaptación en Arica, emergen narraciones sobre procesos de enfermedad que están vinculados a momentos vitales en los que no han logrado resolver con coherencia su posición entre la otredad "propia" y aquella que les fue "añadida en Chile". Los procesos de adaptación son narrados, reiteradamente, como procesos en que las migrantes van aprendiendo a transitar de una a otra posición y condición.

En este sentido, la tercera dimensión dialéctica de la simultaneidad se refiere a la construcción, en los sujetos migrantes, de mecanismos psicológicos y sociales que les permiten vivir de forma sincrónica su constitución como un "yo" y un "otro". Esta constitución, más allá de cualquier bipolaridad analítica, no opera como un par dicotómico en la composición de la personalidad; sino que opera a partir de la experiencia dialéctica de alteridad como algo coherente y constitutivo de una identidad particular. Si las migrantes no lograran encontrar sentido -emocional, racional, psicológico y corporal- en estas transiciones, difícilmente lograrían establecer un proceso de adaptación situacional en Arica de aquellos conocimientos, prácticas, modos de ser y de estar incorporados en origen.

Este proceso de dialéctica composición del principio subjetivo de identidad, no obstante, no sería algo específico del proceso de simultaneidad migrante transnacional. Recuperando el debate de Ricouer (2006) con que empecé el apartado anterior, podríamos considerar que las identidades son compuestas por un doble proceso de comparación, generándose a través de la relación dialéctica entre dos facetas de la existencia de los sujetos. Por un lado, 
tendríamos el idem, que sería la identidad de los sujetos (o grupos) generada cuando ellos se comparan con otros a los que consideran "iguales", proceso que Ricouer denomina mismidad. Por otro lado, tendríamos el ipse, que sería la identidad que los sujetos (o grupos) constituyen a partir de aquello que consideran sus singularidades: las particularidades que no tendrían paralelo con lo que manifiesta el otro externo, constituyendo aquello que el autor acuñó como ipseidad (Clavel et al. 1998: 152; Sodré 1999: 42).

La identidad sería un juego de combinación y cruce entre los elementos resultantes de la comparación idem, y los resultantes de la comprensión particular del sí (ipse). Un juego entre mismidad e ipseidad. Si Ricouer está en lo cierto, entonces toda identidad es una proyección de sentido y de simultaneidad entre la experiencia de "unicidad" y de "otredad". Esta simultaneidad que encontramos en la experiencia del "yo" de los sujetos migrantes no sería entonces cualitativamente diferente de aquello que vivimos todos - migrantes o no- en nuestros procesos identitarios.

La diferencia, la particularidad de la experiencia identitaria de las migrantes peruanas en Arica, estaría puesta en tres elementos. En primer lugar, esta simultaneidad opera a partir del uso estratégico - como es el caso de las peruanas que trabajan en el contrabando de la ropa usada entre Chile y Perú- de la tensión entre lo lícito y lo ilícito en la configuración del área fronteriza. Autores como Grimson (2000a: 28) señalan que la porosidad de las negociaciones sociales en las fronteras, "no implica necesariamente una modificación de las clasificaciones identitarias y autofiliaciones nacionales. Más bien, es sobre la existencia de la frontera que se organiza un sistema social de intercambios entre grupos que se consideran distintos". Esta reflexión sedimenta la consideración de que no porque se cruce cada vez más intensamente las fronteras, éstas dejan de existir. Más que esto, las diferencias jurídicas, políticas, económicas e identitarias entre los espacios nacionales colindantes provocan la emergencia de prácticas sociales que buscan beneficiarse de estas asimetrías (Grimson 200ob) y lo hacen a partir de provocar una liminaridad de la relación entre licito e ilícito y entre pertenencia y desarraigo.

En segundo lugar, esta simultaneidad transnacional del yo de las migrantes utiliza la movilidad y circularidad transfronteriza como un mecanismo fundamental para lograr beneficios e intereses (tanto individuales como grupales o colectivos) derivados de las diferencias entre los territorios de un lado y del otro de la frontera ${ }^{39} . \mathrm{O}$, como ha desarrollado Tapia (2015: 199) en su estudio sobre migración peruana y boliviana en Tarapacá, la circulación y movilidad transfronterizas provocan una forma peculiar de simultaneidad vivida a modo de una "alteridad interactiva" entre espacios locales de un lado y otro de la frontera.

En tercer lugar, esta simultaneidad de la articulación de la alteridad identitaria por parte de las migrantes es un fenómeno que se manifiesta y opera con una intensidad y frecuencia particular. Me refiero con esto que la experiencia migrante - en especial en zonas fronterizas donde la presencia de extranjeros magulla la fibra fuerte del proceso de delimitación de lo nacional, es decir, la necesidad de separar los unos de la nación de sus otros- tensiona a los migrantes a reactualizar constante y frecuentemente la forma como experimentan los procesos de ipseidad y mismidad. Y más que eso, les obliga a entrar y salir velozmente de diferentes formas de estructurar esta relación. En este sentido, y parafraseando a Ricouer (2006), la simultaneidad transnacional implica una constitución del yo migrante en la que el sujeto es recordado, una y otra vez, sobre su condición como un "yo con el otro de yo mismo".

Pero para entender este proceso, es necesario superar al propio Ricouer (2006), en su consideración de que la forma de estructuración de la relación entre el "yo" y su

39 Estos circuitos de movilidad, no obstante, articulan por lo menos tres contradicciones inherentes al establecimiento político de las fronteras y sus regímenes (Cardin 2012: 232). En primer lugar, responden muchas veces a patrones históricos anteriores al establecimiento de las naciones mismas. En segundo, responden también a formas de comercio anteriores a la definición política de lo que se considera ilícito en estos territorios. En tercer lugar, constituyen alternativas para resolver la insuficiencia entre los macro-proyectos económicos aplicados por los Estados en territorios fronterizos en relación a las necesidades de subsistencia de la población que habita estos espacios (Cardin 2012: 232). 
"otro" en el proceso identitario requiere y depende de un proceso diacrónico de enunciación narrativa ${ }^{40}$. Lejos de negar la importancia de la discursividad en la composición de la identidad, reincido en las reflexiones de Comaroff (1985) en su estudio sobre las formas de lucha, resistencia y acomodación de los Tsidi, en Sudáfrica. Como subraya la autora, la interpretación antropológica de la relación dialéctica entre la acción humana y la estructura, y entre ellas y los procesos de construcción del "yo" han sido impactados por el concepto de ideología en la tradición intelectual marxista, el que articula la relación entre práctica social, contexto, conciencia e intencionalidad ${ }^{41}$. Ha predominado, no obstante, la lectura más racionalista, que interpreta la capacidad de intervenir en la realidad social como mediada por formas racionales de conciencia capaces de construirse como o de romper con las ideologías hegemónicas.

Como también apunta Comaroff (1985: 4-5), tanto Foucault (2004) como Bourdieu (2011), se han dado cuenta de la limitación de este concepto explorando en los modos como las formas estructurales lograban producirse y reproducirse desde los sujetos. Esto los llevó a contemplar que la consciencia se produce en la vida cotidiana, en las prácticas sociales, forjando a sujetos que son construidos por las formas sociales y culturales externas a la persona. Foucault (2004) comprende este proceso como parte de la composición del yo-individual en la modernidad, resultado de siglos de violenta construcción de procesos disciplinares que han tenido por efecto la internalización naturalizada de las contenciones y límites sociales y su inscripción en las consciencias individuales.

Bourdieu (2011), a su vez, ha explorado la articulación de los mecanismos de internacionalización con la posibilidad de alguna agencia que, mutatis mutandis, también cambiara la estructura social. Tanto en uno como en el otro, estas formas de internalización adquieren un carácter centralmente corporal. En Foucault (2004), debido a su consideración del cuerpo como recipiente y vehículo de formas sui géneris del poder. En Bourdieu (2011), por la comprensión de que todos los capitales -sociales, culturales, simbólicos, políticos y económicos- solo pueden producirse en la medida en que los sujetos los internalizan a modo de habitus: de "disposiciones duraderas, maneras duraderas de mantenerse y de moverse, de hablar, de caminar, de pensary de sentir que se presentan con todas las apariencias de la naturaleza" (Gutiérrez 2004: 293).

Cada uno a su manera, tanto Foucault como Bourdieu han eclipsado en sus argumentos el papel de la racionalización de la conciencia en la conformación de la experiencia social, en la mediación entre un cuerpo que adhiere y transforma el contexto y que a la vez lo produce y reproduce (Comaroff 1985: 5). Desde mi punto de vista, que es deudor del análisis de Comaroff, el cuerpo y la conciencia constituyen dimensiones dialécticamente imbricadas en la construcción del "yo", y ambos tienen pesos específicos en el proceso social y personal de construcción de la significación de las prácticas sociales.

Los ejemplos dados en el apartado anterior apuntan justamente a esto. En los casos relatados las mujeres nos ofrecían, cuando indagadas por mí, su lúcido análisis sobre cómo habían protagonizado procesos de conformación de su "yo" frente al otro. Entendían y enuncia-

40 Para Ricoeur, las conductas, ritmos y dinámicas de la vida social -que pertenecerían a la dimensión de la identidad comparada (mismidad), a la identidad que se construye en el contacto con los "otros iguales"- invadirían el ipse, el "sí mismo" de las personas y colectivos, a partir de la socialización, a partir de aquello que el autor denomina "hábito". Este último incluiría los "valores, normas, ideales, modelos, héroes, en los cuales la persona y la comunidad se reconocen y que constituyen la identidad de la gente" (Sodré 1999: 44). Los elementos del idem que invaden el ipse condicionan en la identidad del sí una repetición temporal de factores adquiridos socialmente, de factores que pertenecen a la esfera de la alteridad. Esta invasión de la mismidad en la identidad del sí es inestable y requiere una suerte de institucionalización discursiva. En este proceso discursivo, la narratividad tendría una función fundamental, puesto que las imágenes modélicas revividas a partir de la narración - los héroes, los épicos, la moraleja renacida del pasado, las historias sobre los "otros"- serían hilos conductores a partir de los cuales la ipseidad y la mismidad se amalgamarían en un principio identitario, "tanto en el espacio de una subjetividad, cuanto de una comunidad histórica" (Sodré 1999: 45). Esto significa que la convivencia de las nociones de ipseidad y mismidad en esa dinámica identitaria se debe, marcadamente, por la capacidad narrativa de la colectividad para conducir la permanencia del mismo (idem) a partir de modelos de comparación y de enunciación de la singularidad (ipse).

41 La ideología aparece en los escritos tardíos de Marx como doble dimensional: por un lado, como el manejo racional de la conciencia de una clase social o grupo y, por otro lado, como derivada de una experiencia vivida, una "conciencia práctica" (Comaroff 1985:4). 
ban racionalmente la necesidad de estas adaptaciones situacionales. Aprendían de ellas, las compartían entre mujeres en los espacios de concentración femeninos y, en algunos casos, incluso transformaban estos conocimientos sobre el "entrar y salir de la condición del otro" en negocio: ofreciendo enseñar y entrenar a otras mujeres peruanas en este arte, para cruzar la frontera y recibir la visa deseada. En estos procesos, los juegos de identificar a "los otros" a partir de las visiones del "uno" no desaparecen. Pero comprender la diferencia entre esta visión y aquella que tienen los autóctonos se convierte en un punto neurálgico para la supervivencia social. Más que solamente comprender la visión autóctona, las migrantes aprenden y desarrollan estrategias de encuadre que les permiten sentirse como un "yo" coherente en estos procesos adaptativos.

Esto no es un detalle menor para mi argumento sobre la simultaneidad de la construcción del yo - a modo de mismidad e ipseidad intensamente radicales - en la experiencia migrante transnacional. Cuando comprendemos la simultaneidad transnacional como un fenómeno que se inscribe en y desde los cuerpos de los y las migrantes a partir del habitus, observamos que las dicotomías conceptuales son un miraje analítico: ellas no se terminan de sedimentar como pares de oposición en la práctica de las personas. Y esto deviene justamente de la dimensión dialéctica de la experiencia corporal, a medio camino entre objetivación y subjetivación (Comaroff 1985: 6-7). Nos enfrentamos así a la necesidad de caminar hacia una comprensión cada vez más corporalizada de aquellos fenómenos que, en los estudios sobre la migración, denominamos transnacionales.

Ahora bien: el hecho de que el prefijo "des" de descontrol esté entre paréntesis en el título del presente artículo no es casualidad. Esta grafía busca remarcar la relación dialéctica entre control y descontrol en la experiencia transfronteriza de las peruanas en Arica. El control del "yo" por parte de las mujeres reproduce, en muchos aspectos, su imposibilidad de elección en ciertos momentos de su experiencia migratoria. No se trata, consecuentemente, de un control absoluto. Suponer algo así equivaldría a postular una total autonomía del sujeto en relación a los aspectos macro-estructurales que condicionan el contexto social ariqueño. Las estrategias del "yo" les permiten a las mujeres asumir algún nivel de agencia, pero no implican la ruptura de los condicionantes de su posición marginal, de su vulnerabilidad y de los efectos de las clasificaciones interseccionales (de género, de etnia y de clase) que ellas sufren ${ }^{42}$. Asimismo, estas "maniobras" de personificación de su "yo", incluso cuando restrictas a interacciones puntuales y microsociales, pueden ser interpretadas por los Estados fronterizos (a través de sus diferentes agencias locales) como un indicio de su pérdida de poder sobre ellas. Y pueden ser interpretadas como una humillación del otro lado de la frontera, en sus comunidades de origen. Así las cosas, la definición de cuánto hay de control o de descontrol en estas estrategias es un ejercicio analítico que obliga a la investigadora a definir (también dialécticamente) la situacionalidad y los condicionantes contextuales de su propia mirada.

Lo que sí considero fundamental de la experiencia con estas mujeres en Arica, dice relación, centralmente, con la forma como ellas me han enseñado estas estrategias de situacionalidad. Las interpelaciones constantes, el convivir con ellas y observar situaciones en las que entraban y salían de estas condiciones y performances de la otredad, me aportó un sentido y una experiencia de mi condición migrante que hasta el momento no tenía del todo racionalizadas. En otras palabras, he aprendido de ellas que, para sortear las clasificaciones constantes acerca de mi condición extranjera en Arica, tendría yo también que aprender a entrar y salir de esta condición de otredad. Ofrecerle al otro lo que desea, en estas situaciones, no siempre deviene en procesos de sumisión identitaria. Deviene en la posibilidad siempre abierta, desigual e inestable, de proteger los sentidos del "yo". En este juego situacional, las migrantes me han enseñado a, paradójicamente, tomar partido restringiendo mí acción a una interpretación específica de los valores; operando un diálogo cotidiano entre mis sentidos e intenciones particulares, el de los sujetos con que interaccionaba y los condicionantes históricos que configuran los espacios de Arica. Me han enseñado a convivir con la condición de simultaneidad transnacional de mi propio "yo" migrante.

42 Como en el caso de las mujeres del Terminal Internacional de Buses que no aceptan el trabajo ofrecido cuando lo consideran injusto, pero no por esto son capaces de imponer a los contratantes chilenos unas condiciones más justas y humanas de trato. 


\section{$*$ Agradecimientos}

Agradezco a la Comisión Nacional de Investigación Científica y Tecnológica de Chile (CONICYT) que financia este estudio a través del Proyecto FONDECYT 11121177: "Conflictos de género, inserción laboral e itinerarios migratorios de las mujeres peruanas en Chile: un análisis comparado entre las regiones de Arica-Parinacota, Tarapacá y Valparaíso".

\section{* Referencias citadas}

ANDERSON, B. 1993. Comunidades imaginadas. Reflexiones sobre el origen y la difusión del nacionalismo. FCE, México D.F.

APPADURAI, A. 2000. Modernity at large. Cultural dimensions of globalization. University of Minnesota Press, Minneapolis-London.

BARTH, F. 1976. Los grupos étnicos y sus fronteras: La organización social de las diferencias culturales. FCE, México D.F.

BAUMAN, Z. 2006. La globalización: Consecuencias humanas. FCE, México D.F.

BESSERER, F. 2004. Topografias transnacionales. Hacia una geografia de la vida transnacional. Plaza y Valdés Editores, México D.F.

BRENNA, J.E. 2011. La mitología fronteriza: Turner y la modernidad. Estudios Fronterizos 12(24): s/n.

BURAWOY, M. 1998. The extended case method. Sociological Theory 16(1): 4-33.

BURAWOY, M. 2000. Introduction: Reaching for the global. En Global etnography. forces, connections and imaginnations in a postmodern world, T. Gowan (ed.), Berkeley-Los Angeles, University of California Press: 1-40.

CAVIERES, E. 2006. Chile-Perú, la historia y la escuela. Conflictos nacionales, percepciones sociales. Ediciones Universitarias de Valparaíso, Valparaíso.

CLAVEL, J. M.; T. D. MORATALLAy A. O. VELILLA. 1998. Lecturas de Paul Ricoeur. Colección de Estudios. Editorial de la Universidad de Comillas, Madrid.

CLIFFORD, J. 1997a. Spatial practices: Fieldwork, travel, and the disciplining of anthropology. En Anthropological locations. Boundaries and grounds of a field science, A. Gupta y J. Ferguson (eds.), pp. 185-222. University of California Press, Berkeley-Los Angeles.

CLIFFORD, J. 1997b. Routes. Travel and translation in the late twentieth century. Harvard University Press, Cambridge-MassachusettsLondon.
COMAROFF, J. 1985. Body of power, spirit of resistance. The culture and history of a South African People. University of Chicago Press, Chicago.

CRENSHAW, K. 1991. Mapping the margins: Intersectionality, identity politics, and violence against women of color. Stanford Law Review 43(6): 1241-1299.

DEPARTAMENTO DE EXTRANJERÍA Y MIGRACIÓN [DEM]. 2012. Documento Gestión Migratoria. Ministerio del Interior y Seguridad Pública de Chile, Santiago.

DÍAZ A., A. 2006. Aymaras, peruanos y chilenos en los Andes ariqueños: resistencia y conflicto frente a la chilenización del norte de Chile. Revista de Antropología Iberoamericana 1(2): 296310.

EVENS, T. M. S. 2006. Some ontological implications of situational analysis. En The Manchester School. Practice and ethnographic praxis in anthropology, T. M. S. Evens y D. Handelman (eds.), pp. 49-63. Berghan Books, New York-Oxford.

EVENS, T. M. S. y D. HANDELMAN. 2006. The ethnographic praxis of the theory of practice. En The Manchester School. Practice and ethnographic praxis in anthropology, T. M. S. Evens y D. Handelman (eds.), pp. 1-12. Berghan Books, New YorkOxford.

FABIAN, J. 2002. The time and the other. How anthropology makes its object. Columbia University Press, New York.

FABIAN, J. 2007. Memory against culture. Arguments and reminders. Duke University Press, Durham-Londres.

FOUCAULT, M. 2004. Vigiar e Punir: Nascimento da Prisão. Vozes, Petrópolis.

GARCÉS, A. 2007. Entre lugares y espacios desbordados: formaciones urbanas de la migración peruana en Santiago de Chile. Serie Documentos de la Escuela de Sociología de la Universidad Central de Chile 2: 5-22. 
GLICK-SCHILLER, N.; L. BASCH, C. BLANC-SZANTON. 2005. Transnacionalismo: un nuevo marco analítico para comprender la migración. Revista Bricolage 3 (7): 68-84.

GLUCKMAN, M. 2006. Ethnographic data in British social anthropology. En The Manchester School. Practice and ethnographic praxis in anthropology, T. M. S. Evens y D. Handelman (eds.), pp. 13-22. Berghan Books, New York-Oxford.

GONZÁLEZ, S. 1995. El poder del símbolo en la chilenización de Tarapacá. Violencia y nacionalismo entre 1907-1950. Revista de Ciencias Sociales Universidad Arturo Prat 5:42-56.

GONZÁLEZ, S. 2004. El Dios cautivo; las Ligas Patrióticas en la chilenización compulsiva de Tarapacá (1910-1922). LOM, Santiago.

GONZÁLEZ, S. 2007. Ofrenda a una masacre. Claves e indicios históricos de la emancipación pampina de 1907. LOM, Santiago.

GONZÁLEZ, S. 2008. La llave y el candado. El conflicto entre Perú y Chile por Tacna y Arica (1883-1929). LOM, Santiago.

GONZÁLEZ, S. 2009. La presencia boliviana en la Sociedad del salitre y la nueva definición de la frontera: Auge y caída de una dinámica transfronteriza (Tarapacá 1880-1930). Chungara, 41(1): 71-81.

GREENWOOD, D. J. 2000. De la observación a la investigaciónacción participativa: una visión crítica de las prácticas antropológicas. Revista de Antropología Social 9: 27-49.

GRIMSON, A. 2000a. ¿Fronteras políticas versus fronteras culturales? En Fronteras, Naciones e Identidades, A. Grimson (org.), pp. 9-40. CICCUS, Buenos Aires.

GRIMSON, A. 200ob. Cortar puentes, cortar pollos. Conflictos económicos y agencias políticas en Uruguayana (Brasil)-Libres (Argentina). Revista de investigaciones folclóricas, 15: 66-76.

GRIMSON, A. 2005. Fronteras, estados e identificaciones en el Cono Sur. En Cultura, política y sociedad. Perspectivas Latinoamericanas, D. Matto (comp.), pp. 127-142. CLACSO, Quito.

GRIMSON, A. 2011. Los límites de la cultura. Crítica de las teorías de la identidad. Siglo XXI, Buenos Aires.

GROSFOGUEL, R. 2008. Para descolonizar os estudos de economia política e os estudos pós-coloniais: Transmodernidade, pensamento de fronteira e colonialidade global. Revista Crítica de Ciências Sociais 80: 115-147.

GUIZARDI, M. L. 2011. El espacio 'en' y el espacio 'de la' antropología: el debate epistemológico para la etnografía de los fenómenos globales. Gazeta de Antropología de la Universidad de Granada $27(2): s / n$.
GUIZARDI, M. L. 2012. Conflicto, equilibrio y cambio social en la obra de Max Gluckman. Papeles CEIC (88): s/n.

GUIZARDI, M. L. y A. GARCÉS. 2013. Circuitos migrantes. Itinerarios y formación de redes migratorias entre Perú, Bolivia, Chile y Argentina en el Norte Grande chileno. Papeles de Población 19 (78): 65-110.

GUIZARDI, M. L.; O. HEREDIA, A. MUÑOZ, G. DÁVILA y F. VALDEBENITO. 2014. Experiencia migrante y apropiaciones espaciales: una etnografía visual en las inmediaciones del Terminal Internacional de Arica (Chile). Revista de Estudios Sociales 48: 166-175.

GUNDERMANN, H. 1998. Comunidad aymara, identidades colectivas y estados nacionales en los albores del siglo XX. En $A 90$ años de los sucesos de la Escuela Santa María de Iquique, S. González (ed.), pp. 153-181. LOM, Santiago.

GUPTA, A. 1992. The song of the nonaligned world: Transnational identities and the reinscription of space in late capitalism. Cultural Anthropology 7 (1): 63-79.

GUPTA, A. y J. FERGUSON. 1992. Beyond "Culture": Space, identity, and the politics of difference. Cultural anthropology 7 (1): 6-23.

GUPTA, A. y J. FERGUSON. 1997. Discipline and practice. "The Field" as site, method, and location in anthropology. En Anthropological locations. Boundaries and grounds of a field science, A. Gupta y J. Ferguson (eds.), pp. 1-46. University of California Press, Berkeley.

GUTIÉRREZ, A. B. 2004. Poder, habitus y representaciones: recorrido por el concepto de violencia simbólica en Pierre Bourdieu. Revista complutense de educación 15 (1): 289-300.

HASTINGS, A. 2000. La construcción de nacionalidades: etnicidad, religión y nacionalismo. Akal, Madrid.

HANNERZ, U. 2003. Being there... and there... and there! Reflections on multi-site ethnography. Ethnography 4 (2): 201-216.

HARVEY, D. 1989. The conditions of post-modernity: An inquiry into the origins of cultural change. Blackwell, Oxford.

HEIDEGGER, M. 2001. Carta sobre el Humanismo. Alianza Editorial, Madrid.

HOBSBAWM, E. 1998. Naciones y nacionalismo desde 1780. Crítica, Barcelona.

HOLAHAN, D. 2005. El uso de minas terrestres en Chile. Hacia una teoría de la frontera militar. Civitas 5 (2):343-351. 
INE. 2012. Resultados preliminares Censo de Población y Vivienda. Santiago, Instituto Nacional de Estadísticas. Disponible en: http://www.censo.cl/2012/o8/resultados_preliminares_ censo_2012.pdf(consultado 26.05.2012).

KEARNEY, M.1995. The Local and the Global: The Anthropology of Globalization and Transnationalism. Annual Review of Anthropology 24: 547-565.

KEARNEY, M. 2003. Fronteras y límites del Estado y el Yo al final del Imperio. Alteridades 13 (25): 47-62.

KEARNEY, M. 2008. La doble misión de las fronteras como clasificadoras y como filtros de valor. En Migración, fronteras e identidades étnicas transnacionales, L. Velasco (ed.), pp. 79-116. El Colegio de la Frontera Norte, Tijuana.

LEVITT, P. y N. GLICK-SCHILLER. 2004. Perspectivas internacionales sobre la migración: conceptualizar la simultaneidad. Migración y Desarrollo 3: 60-91.

MANZO, E. G. 2010. Las teorías sociológicas de Pierre Bourdieu y Norbert Elias: los conceptos de campo social y habitus. Estudios Sociológicos XXVIII 83:383-409.

MARCUS, G. 1995. Ethnography in/of the world system: The emergence of multi-sited ethnography. Annual Review of Anthropology 24: 95-117.

MCEVOY, C. 2011. Guerreros y civilizadores. Política, sociedad y cultura en Chile durante la Guerra del Pacífico. Ediciones UDP, Santiago.

MILLS, M. B. 2003. Gender and inequality in the global labor force. Annual Review of Anthropology 32: 41-62.

MOCTEZUMA LONGORIA, M. 2008. Transnacionalidad y transnacionalismo. Papeles de Población 14 (57): 39-54.

NÚÑEZ, L. y A. NIELSEN. 2011. Caminante, sí hay camino: Reflexiones sobre el tráfico sur andino. En En Ruta. Arqueología, Historia y Etnografía del tráfico sur andino, L. Núnez y A. Nielsen (eds.), pp. 11-41. Encuentro, Antofagasta.
PASSARO, J. 1997. You can't take the subway to the field!: "Village" Epistemologies in the global village. En Anthropological locations. Boundaries and grounds of a field science, A. Gupta y J. Ferguson (eds.), pp. 147-162. University of California Press, Berkeley-Los Angeles.

PODESTÁ, J. 2011. Regiones fronterizas y flujos culturales: La peruanidad en una región chilena. UNIVERSUM 1 (26): 123-137.

PORTES, A. 2000. Social capital: Its origin and applications in modern sociology. En Knowledge and social capital: foundations and applications, E. L. Lesser (ed.), pp. 43-57. Butterworth-Heinemann, Woburn.

RICOEUR, P. 2006. Sí mismo como otro. Siglo XXI, Buenos Aires.

SATER, W. F. 2007. Andean tragedy: fighting the war of the Pacific, 18791884. University of Nebraska Press, Lincoln.

STAAB, S. y K. H. MAHER. 2006. The dual discourse about Peruvian domestic workers in Santiago de Chile: Class, race, and a nationalist project. Latin American Politics and Society 48 (1):87116.

SEGATO, R. L. 2007. La nación y sus otros: Raza, etnicidad y diversidad religiosa en tiempos de Políticas de la Identidad. Prometeo, Buenos Aires.

SODRÉ, M. 1999. Claros e escuros. Identidade, povo e mídia no Brasil. Vozes, Petrópolis.

TAPIA, M. 2015. Frontera, movilidad y circulación reciente de peruanos y bolivianos en el norte de Chile. Estudios Atacameños 50: 195-213.

VALDEBENITO, F. V. y M. L. GUIZARDI. 2014. Las fronteras de la modernidad. El espacio tacnoariqueño y la nacionalización del Norte Grande chileno (1883-1929). Estudios Ibero-Americanos 40 (2): 277-303.

WALLERSTEIN, E. 2006. Análisis de Sistemas-mundo: una introducción. Siglo XXI, México D.F. 